\title{
Joint Liability and Adaptation to Climate Change: Evidence from Burkinabe Cooperatives *
}

\author{
Pauline Castaing ${ }^{\dagger}$
}

This Version: June 12, 2020

Keywords: Joint liability, Sharing obligations, Climate Change, Adaptation, Burkina Faso

JEL Codes: J43, 012, 013 , 055, Q12, Q54

\footnotetext{
*I thank Catherine Araujo Bonjean and Antoine Leblois for their guidance and support. This paper has been developed using the database of PRISE (Pathways to Resilience in Semi-arid Economies). I would like to acknowledge the guidance of Elizabeth Carabine (Overseas Development Institute, ODI) and Catherine Simonet (ODI) who developed the survey and the data collection strategy. I also acknowledge national team, supervised by Denis Akouwerabou, who implemented the data collection in Burkina Faso. This paper has been improved thanks to comments received at the EAERE Conference in Manchester, JMA Conference in Casablanca and the seminars held at University of Clermont-Ferrand and University of Lorraine. Finally, this work benefited from the helpful suggestions from the two anonymous reviewers. I acknowledge the support received from the Agence Nationale de la Recherche of the French government through the program "Investissements d'avenir" (ANR-10-LABX-14-01).

†CERDI, Université Clermont Auvergne. E-mail: pauline.castaing@uca.fr
} 


\begin{abstract}
In semi-arid lands, the resilience of farmers facing climate change is uncertain. The main objective of this paper is to explore whether mutual assistance within a group of cotton farmers implies reduced adoption of risk-mitigating strategies. I investigate the case of Burkina Faso where cotton farmers collectively purchase inputs from the cotton wholesale companies and pay for their purchase under the constraint of joint liability. Specifically, I try to understand whether this joint liability is correlated with the adoption of strategies which reduce exposure to climatic risks. I proxy peer pressure by the size of the network and find it to be associated with reduced investment in both incremental and transformational self-protection against weather shocks.
\end{abstract}

JEL Codes: J43, O12, O13, O55, Q12, Q54

Keywords: Sharing obligations, Group lending, Climate change, Adaptation, Burkina Faso. 
A wide variety of risks, including climate-related risks, threatens the African agricultural sector. In Africa, agriculture is mostly rain-fed and depends heavily on precipitation, which varies intra-annually, inter-annually, and spatially (Sivakumar, 1988; Sultan et al., 2005). Observations of past data in Sub-Saharan Africa have shown an increasing variability of climatic variables in recent decades, and this trend is expected to continue during the 21st century (Cook and Vizy, 2006; Kotir, 2011; Field et al., 2014). There are large regions of Sub-Saharan Africa where climate change will affect agricultural production and make farmers reconsider their management systems in favour of more resilient strategies. Burkina Faso, where cotton production is at the core of many households' livelihoods, is one of them. The cotton yields in West Africa have been shown to be very sensitive to 3 main climatic features: rainfall, humidity and temperature, and solar radiation (Blanc et al., 2008).

Climate variability will continue to affect cotton yields in Burkina Faso and reinforce the need for adaptation. Geographic and socio-economic environments shape a household's choice of adaptation strategies, by fostering, or constraining, its ability to adapt. The socio-economic characteristics of the household, market conditions, biophysical aspects, characteristics of adaptation practices, and other local features are key determinants for the implementation of climate risk mitigating strategies (Hassan and Nhemachena, 2008; Bezabih and Sarr, 2012; Bryan et al., 2013; Angelsen et al., 2014; Antwi-Agyei et al., 2018). This paper investigates an additional factor associated with adaptation to climate change which has been rarely, considered in the economics literature: mutual assistance between farmers. Specifically, the purpose of this paper is to understand whether mutual assistance inside cooperatives correlates with a willingness to self-protect against climate change.

To reduce the risks of agricultural activities, risk-pooling via both formal and informal structures is a normal approach. In Burkina Faso, a compulsory risk-pooling mechanism has been implemented in the cotton sector to protect farmers from negative shocks. Cotton farmers are gathered into formal groups to get access to inputs from cotton companies. At the end of the agricultural season, producers must pay back their own part of the loan to the company through harvested crops. The joint liability system is one of the key components of risk-pooling in this organization. ${ }^{1}$

\footnotetext{
${ }^{1}$ In this case joint liability denotes the obligation of two or more partners to share responsibility
} 
This system implies that the crop failure of one farmer must be compensated by other farmer members of the group. Sharing obligations within their professional network allow farmers to mitigate harmful impacts from shocks. However, this sharing may come at a cost, because of potential negative incentive effects. Compulsory sharing generates free-riding behaviour by reducing the incentives for self-protection as farmers can fall back on other members. Sharing obligations may dissuade farmers from working hard, or investing in infrastructure, because the more successful farmers are likely to be forced to assist other members of the network.

The cotton sector in Burkina Faso provides a clear example to better understand the interplay between risk-pooling strategies and individual farmer's management decisions against the threat of climate change. This paper aims to make two main contributions. First, it explores the behavioural impacts of redistributive pressure in the farmers' professional network. A professional network has rarely been considered as a source of pressure in academic studies, especially when compared to kinship ties. Yet cooperatives are professional environments where the joint liability condition puts pressure on farmers. This paper provides information for policy makers and cotton companies about the effects of sharing obligations by conducting a study in Burkina Faso where the economic implications of cooperatives have not yet been analysed. Pointing out the adverse effects of purchasing in a joint liability mechanism in agricultural activities is important, because this form of organization is legally enforced in the whole of Burkina Faso, and acts as a role model for neighbouring states involved in cotton growing, such as Mali and Cameroon.

The second original feature of this paper is to identify two types of adaptation strategy and analyse how each of them is correlated with group lending. Over the years, farmers have undertaken important strategies and practices to adapt to climate-related risks and reduce their vulnerability (Thomas et al., 2007; Bezabih and Sarr, 2012; Bryan et al., 2013; Elum et al., 2017). The Intergovernmental Panel on Climate Change (IPCC) suggests a categorization for these strategies: "incremental" or "transformational" (Field et al., 2014). Incremental adaptations involve efforts to make existing locations, livelihoods, and systems more resilient to climate change. For cotton production in Burkina Faso, incremental adaptations by farmers might consist of improving soil and water conservation techniques, both crucial for making a payment. 
to an optimal crop growth. ${ }^{2}$ However, undertaking exclusively incremental adaptations may lead to a maladapted response in the long term, because the risk of rainfall variability is expected to increase and threaten rain-fed agricultural production. Some authors argue that instead of trying to preserve existing practices, adaptation strategies in developing countries need to become more transformational (Kates et al., 2012; Castells-Quintana et al., 2018). By transformational, they mean adaptation strategies which aim to reduce vulnerability to climate change through geographical and sectoral mobility of poor people.

To guide the empirical analysis, I use a sample of 668 cotton producers from semi-arid regions of Burkina Faso interviewed during the 2015/2016 agricultural season. I use a probit model, and some extensions as robustness checks (biprobit and ordered probit models), to show that sharing obligations encourages free-riding and reduces the incentives for self-protection against climate change. Instrumental variables are added to the analysis to deal with endogeneity of the network variable. Given that the survey is only conducted for one agricultural season, the different specifications cannot control for potential time invariant characteristics. A causal inference approach would require some additional observations of farmers' perceived pressures that are not available in the questionnaire. This work aims to highlight the correlations between cooperative decisions and individual decisions to adapt to climate change.

The results show that risk-pooling strategies operate at the expense of selfprotection techniques to protect against climate change. This distortion effect has an impact on both incremental and transformational strategies, hampering the adoption of risk-mitigating strategies beyond the case of cotton management. This result is stronger when farmers report that they belong to groups that facilitate both money transfers between members and adaptation to climate change. This supports the hypothesis that the disincentive to adapt partly comes from the joint liability mechanism at the core of the system.

The remainder of this paper is organized as follow: Section 1 describes the organization of cotton producers in Burkina Faso and relates it to literature and theoretical intuition on sharing obligations. Section 2 introduces the research ques-

\footnotetext{
${ }^{2}$ The common soil and water conservation techniques in Burkina Faso include zai, mulching, diguettes (rock bunds), half-moons, and hedgerows.
} 
tion, the econometric strategy and the data. In section 3, the main results along with some robustness checks are discussed. Section 4 concludes.

\section{Context, Literature, and Theoretical Basis}

\section{The system of Cotton Farmers' Groups}

For Burkina Faso, which is a landlocked country, cotton production has been a vital source of export earnings driving economic growth. Over recent decades, Burkina Faso has become the largest cotton producer in West Africa. Being highly dependent on agriculture, Burkina Faso's economy is threatened by shocks that affect crop and livestock agricultural activities, such as weather, pests, and diseases.

The Sudanese and Sudano-Sahelian agro-ecological zones are today the major areas of cotton production. With an average annual rainfall of $600-900 \mathrm{~mm}$, the Sudano-Sahelian zone is classified as a semi-arid region; whereas the Sudanese zone with 900-1100 mm is classified as a sub-humid environment (see Figure 1). Farmers are scarce in the Sahelian zone where the arid environment makes growing cotton difficult.

Beginning with the French colonial period and then after independence, the Burkina Faso cotton sector has been mainly owned and managed by French investors and local governments (Schwartz, 1996). After the independence of Burkina Faso, SOFITEX, a state organization, and CFDT, a privately-owned French company were responsible for the cotton sector. Cotton processing and marketing was a system in which SOFITEX provided all the inputs to cotton farmers and were given exclusive rights to purchase the cotton produced by the farmers (Schwartz, 1996). This vertically integrated system reduced the profits of cotton farmers who were left with only a small percentage of the world cotton price.

In 2002, new institutional arrangements reduced the monopsony control of SOFITEX and opened the cotton market to two other companies - Faso Coton and SOCOMA, which operated in different regions of the country. At the same time, the Burkina Faso government partially reduced its ownership to $35 \%$ to leave more space for other stakeholders in the leadership of the cotton sector. In this new envi- 
ronment, producers contribute to the negotiation of price levels through a farmers' union called the National Union of Cotton Producers of Burkina Faso (UNPCB). Although some organizational transformation occurred, the cotton sector is still characterized by a high degree of vertical integration. Upstream, the cotton companies act as a monopsony by providing farmers with inputs, credit, and other extension services. Downstream, it operates as a monopoly by purchasing all the cotton harvest from the farmers (Vitale, 2018). Figure 1 illustrates the distribution of land between the three cotton companies operating in Burkina Faso.

The 2002 emancipation of cotton farmers in Burkina Faso occurred following a reform in 1996. Before that, farmers were organized under cooperatives through village-scale joint liability schemes called the GV ("Groupements villageois"). With the 1996 reform, the former GVs were replaced by cooperatives called Cotton Producers' Groups (GPC). ${ }^{3}$ Under this new arrangement, cotton farmers were supposed to group together by affinity and social preference. These new cotton farmers' organizations, controlled by monitoring and joint liability, generated significant improvements both at the farm level (Kaminski and Thomas, 2011; Kaminski, 2014) and on more aggregated agricultural indexes (Kaminski et al., 2011).

Therefore, every Burkina Faso cotton farmer belongs to a GPC. Within the group, farmers are bound by a joint liability to the relevant cotton company. Prior to planting, each farmer informs her GPC about their needs in terms of inputs mainly seeds and fertilizers. Cotton firms provide the aggregated amount of inputs requested by the GPCs which redistribute them to farmers. At the end of the agricultural season, farmers must pay for their inputs by means of harvested crops, so that they eventually receive the production value reduced by the value of the debt. If one member of the group fails to provide enough crops to meet their liability, other farmers from the same group take over the debts. This organization within the Burkina Faso cotton sector is very close to the concept of group lending programs which provide credit to an individual borrower who is herself a member of a borrowing group. This means that all group members are treated as being in default if any member of the group does not repay their debt.

If a shock affects the income of one of the group members, the sharing rule

${ }^{3} \mathrm{GPC}$ is the acronym of Groupements de Producteurs de Coton, the French and commonly used expression for Cotton Producers' Groups. 
dictates that other farmers should provide assistance in the form of supplementary harvested crops. I expect these sharing obligations to impact decisions of production of farmers threatened by climate change. Different hypotheses can be formulated about the consequences of such a system on resilience behaviours. The literature on group lending and sharing obligations provides tools to predict how the system enforced in the Burkinabe cotton sector may affect risk-taking behaviours.

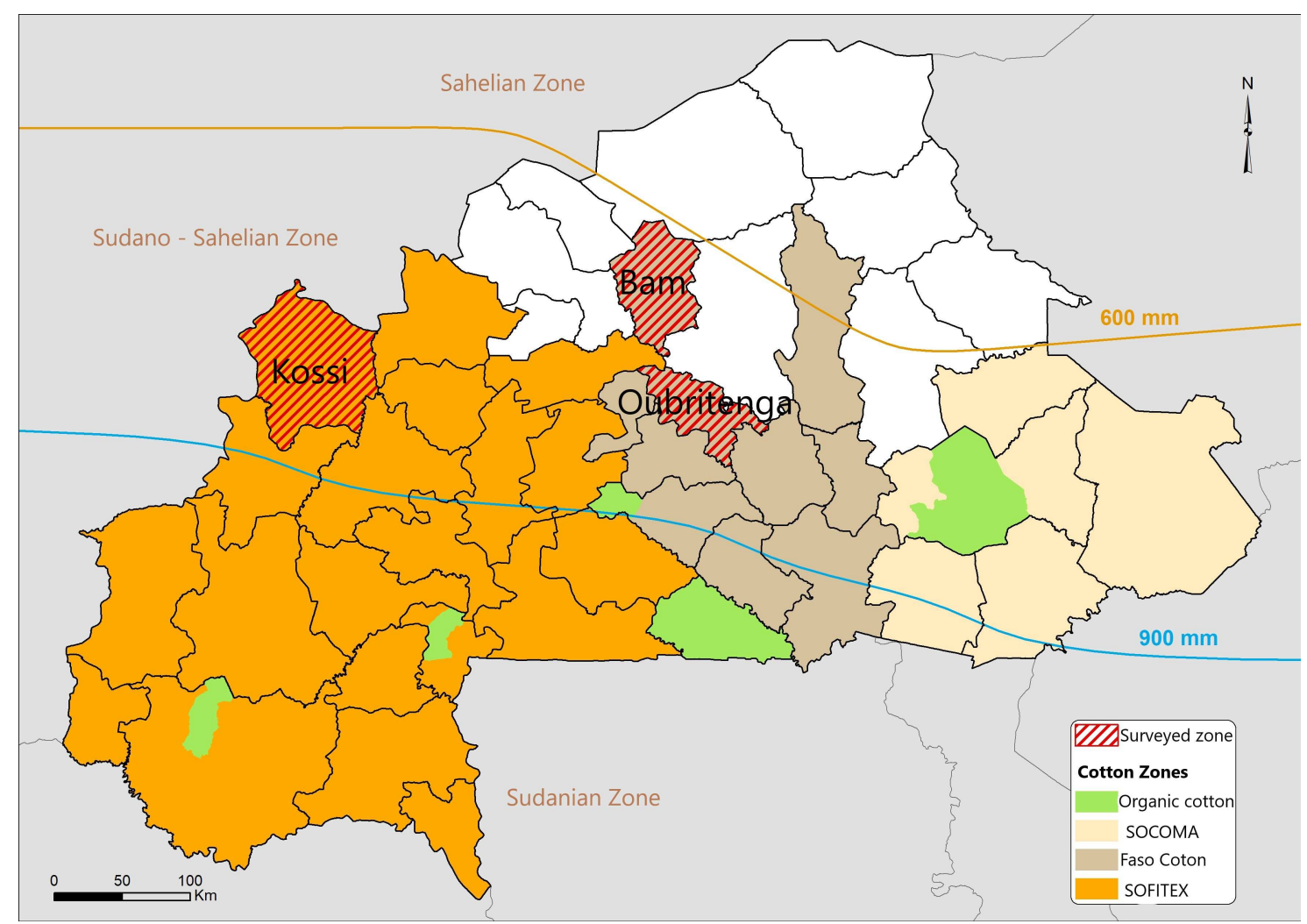

Figure 1: Map of Burkina Faso with rainfall, cotton growing areas, and cotton companies

\section{Literature on sharing obligations}

This paper investigates the potential presence of forced solidarity in agricultural co- operatives. Forced solidarity generally refers to the sharing of obligations that may occur and have negative effects on savings and investments. ${ }^{4}$ These sharing obligations come from norms and traditions (within households) or are imposed by a system (such as group lending in cooperatives). The literature on the adverse impact

\footnotetext{
${ }^{4}$ In sociology, solidarity relates to strong feelings of social cohesion and togetherness (Durkheim, 1997).
} 
of forced solidarity mostly applies to networks characterized by strong ties, such as kinship. This Burkina Faso case study deviates from this literature, and considers the professional network of cotton farmers as a new framework in which adverse effects of peer pressure may occur. The joint liability mechanism in cooperatives requires farmers to redistribute their harvests towards less productive members, imposing a kind of mutual assistance between them. In addition, the vulnerability of farmers to climate change in these semi-arid regions generally creates some "ingroup feelings" in the sense that a common threat boosts social cohesion (Cassar et al., 2011; Voors et al., 2012). Therefore, I believe that a solidarity framework model is suitable for capturing farmers' mutual help in cooperatives, and in-group feelings, in a rural environment where people are frequently exposed to shocks.

Granovetter (1983) makes a distinction between strong ties and weak ties, and considers business networks to be included in the latter. ${ }^{5}$ Following Granovetter, the ties binding members from a cooperative can be regarded as weak ties. In his work, he highlights the strength of weak ties in providing new opportunities and shows that the acquaintances outside one's network offer new sources of information about the job market. In the specific context of agriculture in Burkina Faso, the cooperative may represent new opportunities for a farmer to depend on extra income in case of failure of her own harvests, because the inner circle of ties, which are strong ties, might have also been affected by the shock and so may not represent a source of assistance. However, new opportunities brought by weak ties do not translate only into positive economic impacts. For instance, Patacchini and Zenou (2008) show that a higher prevalence of weak ties increases the crime rate in the American economy because delinquents and non-delinquents are in close contact. I now review some adverse effects that could be at stake when weak ties are grouped under joint liability constraints.

Besley and Coate (1995) make the point that group lending may be able to harness social collateral. Under joint liability systems, borrowers may fear the reaction of other group members. If the group is formed with a high degree of social connectedness, this fear may constitute a powerful incentive device, since the costs of upsetting other members in the community may be high. The fear of being socially sanctioned may enhance cooperative members' incentives.

\footnotetext{
${ }^{5}$ Weak ties are acquaintances and strong ties are close friends.
} 
However, the relatively more successful members of social groups would face internal pressures to redistribute their incomes, which would create disincentives to apply effort, take risks, and accumulate capital (Platteau, 2014). The sharing rule compels the more successful members to bear the burden of the less successful in the network. The imperative to redistribute resources may be closer to an informal redistributive tax. Like any tax, this mechanism carries the threat of potential evasive response from the most prosperous members (Platteau, 2000; Baland et al., 2011; Squires, 2016). Experimental evidence supports this view, and research has investigated the magnitude of the economic impact of social pressure to share income with kin and neighbours (Beekman et al., 2015; Jakiela and Ozier, 2016; Boltz et al., 2019). For instance, in Tanzania, Di Falco et al. (2018) show that farmers with higher expected harvests discussed seed type with fewer people and obtained fewer actual harvest gains.

From the literature, two ways of managing production or income in response to redistributive pressure from a network can be distinguished. On the one hand, altruism creates an empathy effect and so an incentive to reduce the probability of having to draw on one member's resources. On the other hand, a free-rider effect creates both the temptation to rely on the efforts of other producers, as well as the disincentive to make effort since returns from such investments might be shared with less successful members.

In Burkina Faso, sharing norms are generally strong (Englebert, 1996). Hadness et al. (2013) investigate the productivity level of a small sample of Burkina Faso tailors depending on whether their prospective income was public information in their solidarity network or not. Their results show that compulsory sharing, as well as the expectation of future claims for financial support, significantly hinder entrepreneurial activity. Similarly, Grimm et al. (2017) show that forced redistribution through family and kinship reduces the ability to invest in capital for businesses in Ouagadougou. The empirical evidence based on these two papers finds free-riding behaviours rather than an empathy effect in response to compulsory sharing. Whereas the redistributive pressure from strong ties has been well studied in Burkina Faso, no research has focused on the potential adverse effects which might be driven by the professional network itself. However, feedback from the field has 
shown evidence of a high prevalence of peer pressure in cotton cooperatives ${ }^{6}$

An under-explored research question is the extent to which this response may lead to to ill-suited economic decisions in the context of climate change. For instance, would individuals reduce their efforts dedicated to their cotton production to avoid resource sharing with their peers? Inversely, would they put additional efforts into production to avoid crop failure and assistance from other members? These questions emphasize the potential impact of a network on incremental adaptation strategies. Intuition first drives me to expect an impact of mutual assistance between farmers on decisions regarding the management of the cotton sector itself, namely incremental adaptations. A further concern occurs regarding transformational adaptations. That said, does the group buying scheme also hamper cotton growers from moving across sectors and space?

\section{Theoretical Basis}

In this section, I introduce the theoretical background to look at the impact of peer pressure on the level of effort involved in agricultural production. This is mainly inspired from the work developed by Armendáriz de Aghion (1999) in which she describes the key parameters to take into account in order to optimally design a collective credit agreement with joint liability. Specifically, she studies how the size of the group has an impact on the level of effort involved in production. She shows that a too large group size prevents an optimal arrangement because of the free-riding effect. Armendáriz de Aghion (1999)'s theoretical model is of particular interest to describe how the size of a network may affect the level of productive effort when joint liability is at the core of the system.

In this section, I try to explain the design of farmers' groups in the Burkina Faso cotton sector and deviate from Armendariz de Aghion's model by assuming that the levels of effort and output are common knowledge between members. The aim here

\footnotetext{
${ }^{6} \mathrm{~A}$ quotation from Paul Gbangou, former cotton producer in Burkina Faso, has been translated into English for the purpose of this paper: "I had to leave the cotton agricultural sector because of GPC. It was exhausting. You work and earn a good harvest, but still suffer at the end because of other farmers who did not work enough." This comes from De Graeve et al. (2017), https://www.bastamag.net/ De-la-Francafrique-a-la-corruption-les-dessous-de-la-filiere-coton-au-Burkina .
} 
is not to solve the equilibrium of the game between actors but rather to understand how an increase in group size will change incentives for effort. Thus, the focus is on the impact of the redistributive pressure, proxied by group size, on productive decisions.

Under the condition that farmers can observe their partners' efforts, they know that there is a desirable Pareto-optimal level of effort which they need to commit to if they want to maximize the joint profit of the group: this is called the cooperative level of effort $e^{c}$. If farmers decide to maximize their individual profit level, they play a non-cooperative game with level of efforts $e^{n c}$. The model first describes the simplest form in which the group includes only 2 farmers, then increases the group size later.

Let us consider that each cotton farmer owns 1 unit of land and asks for 1 unit of input to produce cotton. They either obtain a successful harvest $Y=\bar{Y}$ with probability $e$ or an unsuccessful harvest $Y=\underline{Y}$ with probability $1-e$. Farmers chose actions, which can be thought of as a level of effort $e \in[0,1]$, for which they incur a strictly convex disutility $\operatorname{cost} C(e)=c e^{2} / 2$. Farmers are considered to be risk neutral. Cotton companies and farmers' unions establish the cotton fibre output price $(p)$ and the input prices for farmers $(w)$. At the beginning of the agricultural season, farmers take the prices as given, and make efforts in the production to pay back their debt. At the end of the agricultural season, they are paid $p$ for their output but the input value $w$ is subtracted from their payment. I assume that the farmer can repay her debt only when the output is high enough $(Y=\bar{Y})$, otherwise she defaults and relies on her partners.

In the first case of two symmetric farmers linked by a joint liability agreement, the group defaults when both farmers have poor harvests, as

$$
p \bar{Y}-w>0>p \underline{Y}-w
$$

and,

$$
p \bar{Y}-w>p(\bar{Y}+\underline{Y})-2 w>0
$$

Under the joint liability agreement, each farmer's ex-ante expected profit $\pi^{i}$ can 
be written as:

$$
\pi^{i}=e^{2}[p \bar{Y}-w]+e(1-e)[p \bar{Y}+p \underline{Y}-2 w]-C(e)
$$

To make it clearer, both cotton producers realize successful harvest $\bar{Y}$ with probability $e^{2}$ so that they earn $p \bar{Y}-w$. The probability of 1 farmer defaulting is $e(1-e)$ ), so that farmer $i$ receives her own surplus from a successful harvest minus the other's deficit, $p \bar{Y}+p \underline{Y}-2 w$.

I next derive the optimal efforts made by farmers when they are jointly liable, to compare it to its counterpart for larger groups, and I derive the optimal efforts for both the cooperative and non-cooperative situations. Within the framework of cooperative efforts, the farmer maximizes the total welfare of the group which ultimately means considering the partner's effort as given and exogenous (noted $\bar{e}$ ). The optimization of equation (3) offers the optimal non-cooperative effort $e^{n c}$ as the solution of

$$
\max _{e} \pi^{i}=e \bar{e}[p \bar{Y}-w]+e(1-\bar{e})[p \bar{Y}+p \underline{Y}-2 w]-c e^{2} / 2
$$

Using the first order condition and stating $e=\bar{e}$ since a farmer displays symmetric characteristics,

$$
\bar{e}[p \bar{Y}-w]+(1-\bar{e})[p \bar{Y}+p \underline{Y}-2 w]=c e,
$$

it is now possible to find $e^{n c}$ so that

$$
e^{n c}=\frac{p \bar{Y}+p \underline{Y}-2 w}{p \underline{Y}-w+c}
$$

The sufficient condition to ensure an interior solution is

$$
w-p \underline{Y}<p \underline{Y}-w<c .
$$

In the case of endogenous effort from other farmers, the optimal cooperative effort is given by

$$
\max _{e} \pi^{i}=e^{2}[p \bar{Y}-w]+e(1-e)[p \bar{Y}+p \underline{Y}-2 w]-c e^{2} / 2
$$


It implies the following optimal level of cooperative effort

$$
e^{c}=\max \left(\frac{p \bar{Y}+p \underline{Y}-2 w}{2 p \underline{Y}-2 w+c}, 0\right)
$$

with $e^{c}<1$ under (6).

For the given parameters $(p, w, \bar{Y}, \underline{Y}, c), e^{c}>e^{n c}$ if and only if,

$[p \bar{Y}+p \underline{Y}-2 w][p \underline{Y}-w+c]>[p \bar{Y}+p \underline{Y}-2 w][2(p \underline{Y}-w)+c]$,

which is always true if equation (2) applies.

Extension to larger groups : The theoretical model developed so far has considered the case of only 2 farmers and depicts a situation where effort is assumed to be higher when farmers cooperate. The next question is how efforts would modify if there is a change in the size of the cooperative network? Now, I present the results of the optimal level of effort for n-symmetric farmers.

When turning from a one-to-one situation to a larger group, incentives for efforts are changed in both cooperative and non-cooperative contexts. More farmers in the group means more members to share the deficit of defaulting producers and the probability of more farmers in default. Thus, the size of the group impacts the probability of the distribution of ex-ante expected profits.

With n-symmetric risk neutral cotton producers, the cooperative effort resulting from joint-profit maximizing is solved for

$$
\max _{e} \sum_{k=0}^{k=n / 2} C_{n-1}^{k}\left[e^{n-k}(1-e)^{k}\right]\left[p \bar{Y}-w+\frac{-k(w-p \underline{Y})}{n-k}\right]-C(e)
$$

Under the cost function specified previously, the first-order condition that determines the optimal effort of a $n$ sized group is

$$
\sum_{k=0}^{k=n / 2} C_{n-1}^{k}\left[p \bar{Y}-w+\frac{-k(w-p \underline{Y})}{n-k}\right]\left[e^{n-k-1}(1-e)^{k-1}\right][(n-k)(1-e)-k e]=c e=\Gamma^{c}(e, n, \Omega)
$$

where $\Omega$ is a vector of parameters $p, \bar{Y}, \underline{Y}$ and $w$. 
If now, the farmers maximize their individual profit and take others' effort as exogenous, the new optimization is :

$$
\max _{e} e \sum_{k=0}^{k=n / 2} C_{n-1}^{k}\left[\bar{e}^{n-k-1}(1-\bar{e})^{k}\right]\left[p \bar{Y}-w-\frac{k(w-p \underline{Y})}{n-k}\right]-C(e)
$$

he farmer's problem in the cooperative context leads to the following first order condition

$$
\sum_{k=0}^{k=A(n)} C_{n-1}^{k}\left[p \bar{Y}-w-\frac{k(w-p \underline{Y})}{n-k}\right] e^{n-k-1}(1-e)^{k}=c e=\Gamma^{n c}(e, n, \Omega)
$$

The first observation is that $e^{c}>e^{n c}$ as long as $\Gamma^{c}(e, n, \Omega)>\Gamma^{n c}(e, n, \Omega)$ $\forall(e, n, \Omega)$. Thanks to previous assumptions made on $\Omega$ and the virtue of marginal costs increasing with effort, this finding remains true.

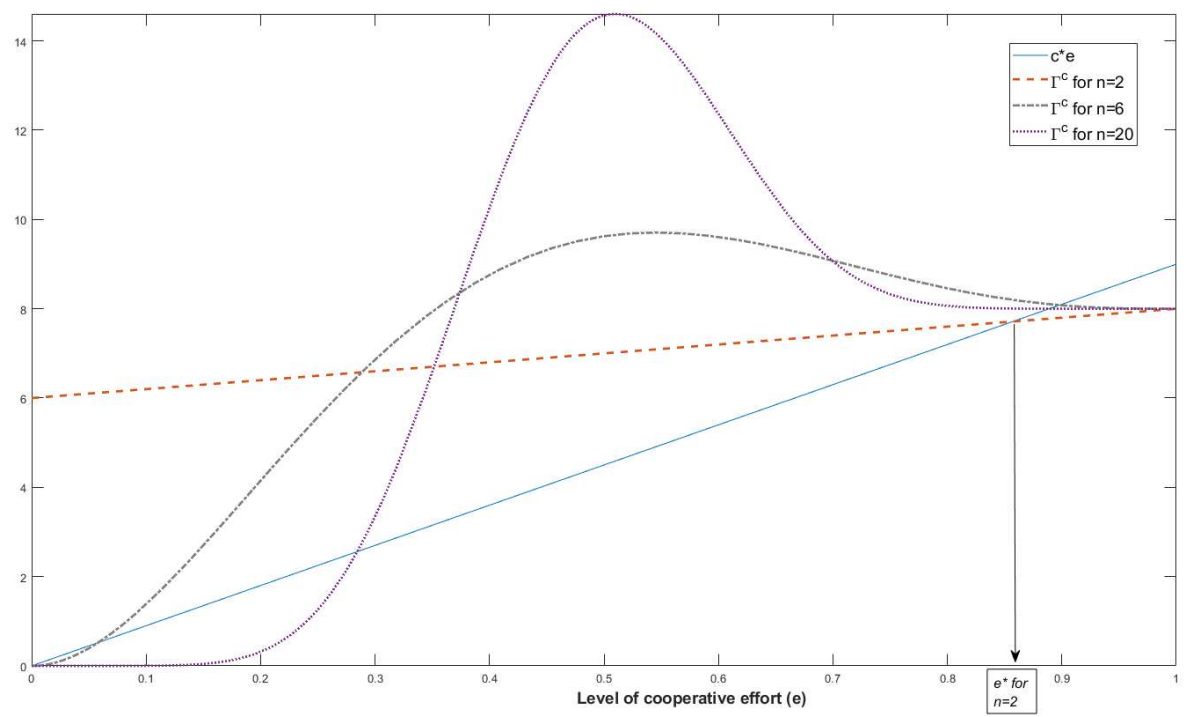

Figure 2: Cooperative equilibria of the n-player game.

From here, I analyse how the optimal efforts in both cooperative and noncooperative contexts react to an increase in the size of the group. I simulate $\Gamma^{c}$ and $\Gamma^{n c}$ in figures 2 and 3 to graphically identify the optimal level of effort for 


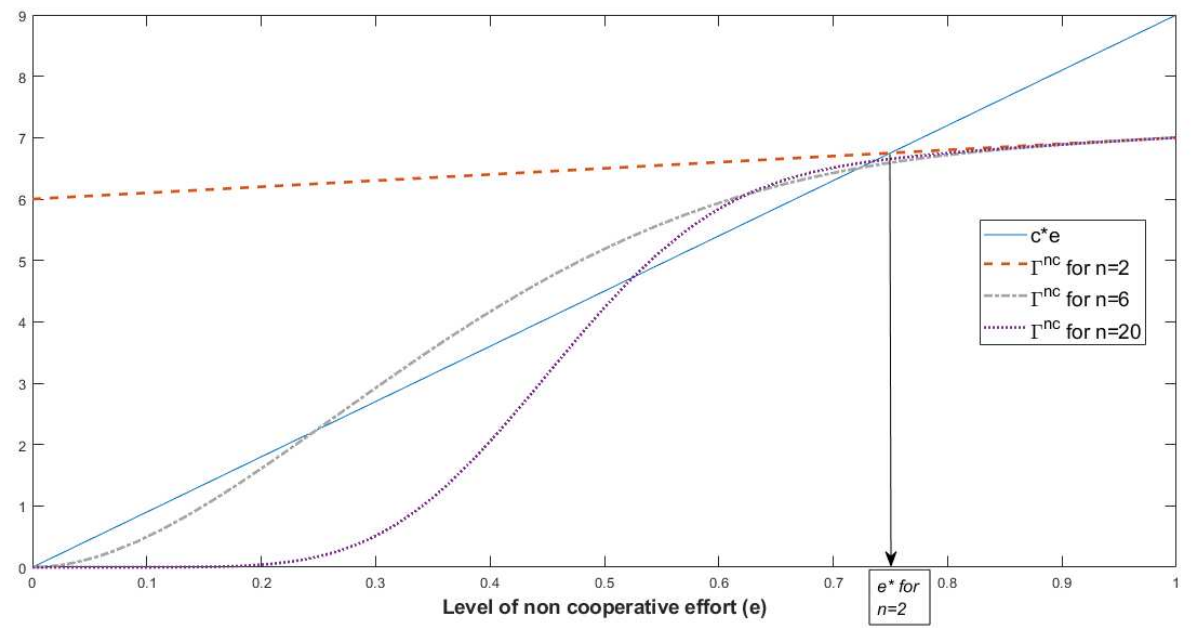

Figure 3: Non Cooperative equilibria of the n-player game.

different group sizes $(\mathrm{n}=2, \mathrm{n}=6 \text { and } \mathrm{n}=20)^{7}$.

Figure 2 shows that an increase in the size of the professional network generates an ambiguous effect on the optimal level of effort chosen by the farmer. For instance, the optimal cooperative level of effort equals 0.86 when there are only 2 farmers and rises to 0.90 when the group increases to 6 members. However, there seems to be a network size threshold over which farmers belonging to larger groups start to reduce their optimal efforts on agricultural activities $(e *(n=20)<e *(n=6))$. For the non-cooperative framework, the simulated optimal level of effort firstly falls with the increasing size of the network before it rises again. However, optimal efforts in production in Figure 3 are always lower than in the case of a 2-player game.

This basic model developed for the specific case of joint liability agreement between cotton producers in Burkina Faso can be encapsulated in the seminal work of Armendáriz de Aghion (1999) which disentangles several effects of the size of the net- work on borrowers' behaviour. The free-riding effect implies that a larger group size discourages individual monitoring effort whereas other effects counteract it. The figures above illustrate the ambiguous impact of the increase in the size of the network when joint liability agreement is at the core of the system.

In what follows, I liken the variable $e$ to the level of effort to adapt to climate change. I seek to test the prediction that cotton producers' ties affect self-protection

\footnotetext{
${ }^{7}$ To allow for simulations, I assign values to parameters in the vector $\Omega$ while respecting assumptions (1), (2) and (6).
} 
against climate change in Burkina Faso. The econometric analysis helps to solve the directional ambiguity of this impact.

\section{Data and statistical model}

\section{The sample survey}

Data for this study come from Pathways to Resilience in Semi-Arid Economies (PRISE), a multi-country research project which has the aim of generating new information about how economic development in semi-arid regions can be made more equitable, and more resilient to climate change. ${ }^{8}$ Alongside other case studies, Burkina Faso was considered in analysing the cotton sector in Semi-Arid Lands. To be part of the survey, provinces from Burkina Faso needed to meet several criteria. First, they must have a semi-arid environment to meet the terms of the PRISE project. Second, they must have some cotton farmers. ${ }^{9}$ Third, the cotton companies operating in the selected departements must be SOFITEX and Faso Coton. ${ }^{10}$ The researchers worked closely with these two major cotton companies which both agreed to provide a list of cotton producers in the departements of interest.

Following these criteria, three provinces were represented in the survey: Kossi where SOFITEX operates, and Oubritenga and Bam where Faso Coton operates. In the Oubritenga province, households for which the main economic activity consists in farming cotton are located in two departements: Nagreongo and Absouya. In total, these two departements have 160 farmers. The province of Bam has 475 cotton farmers in 5 departements (Kongoussi, Rollo, Tikaré, Sabcé, and Guibaré). Due to the small number of cotton farmers in these semi-arid regions, an exhaustive survey was initially considered there. However, out of the 635 listed farmers in these two provinces, only 524 were present at the time of the survey.

Unlike Bam and Oubritenga, the province of Kossi is a major cotton production

\footnotetext{
${ }^{8}$ This project is led by Overseas Development Institute (ODI).

${ }^{9}$ Although this requirement sounds obvious, some arid or semi-arid agroclimatic zones do not have any cotton producers because of difficult growing conditions for this.

${ }^{10}$ Departements in Burkina Faso represent the third administrative division, after Regions and Provinces. They are equivalent to the county level.
} 
zone with approximately 6,033 farmers allocated between 8 departements. According to information available from SOFITEX, only Nouna and Doumbala departements have a semi-arid environment. ${ }^{11}$ Therefore, an additional sample of 144 farmers who grew cotton during the 2015-2016 season was surveyed there. 668 farmers were surveyed in December 2016.

Descriptive statistics for the independent variables are presented in Table 1, which provides information on several household characteristics - age, literacy, a wealth indicator ${ }^{12}$, and agricultural characteristics - the area of land used for cotton production and the labour used per unit of land. For the labour variable, the survey distinguished between male and female employees and between family and paid employees, but I aggregate this information into one labour measure. The labour measure is defined by the total number of workers divided by land units.

The summary table also presents the links of the households to the outside world, including whether the household had access to early warning systems about extreme weather events. Furthermore, it introduces information on the perceived benefits of the GPC system at the individual level. Farmers were asked whether their GPC helps them to adapt to climate change. Later in the questionnaire, they were asked to identify 3 channels through which they take advantage of their GPC. I create a dummy variable equal to 1 if the farmer reports "money transfers between farmers" to be one of the benefits from a group. ${ }^{13}$

Given the dependence on climatic conditions for farming success, I collected monthly rainfall and temperature data using GPS coordinates from the households. Data on rainfall were extracted from CHIRPS database from 1994 to 2016 and allowed computation of cumulative rainfall levels for the agricultural season (from May to October) for each year (Funk et al., 2015). ). I calculate the ratio of average cumulative rainfall from 2005 to 2016 over average cumulative rainfall from 1994

\footnotetext{
${ }^{11}$ SOFITEX uses its own devices to measure rainfall and temperature where its clients are located.

${ }^{12}$ The wealth index was constructed following the methodology proposed by the DHS Program, taking into account characteristics such as assets and housing conditions. See https://www . dhsprogram.com/topics/wealth-index/Wealth-Index-Construction.cfm

${ }^{13}$ The questions about help on climate change and channels are independent. A farmer who answers that his/her GPC does not help to adapt to climate change can still choose 3 benefits from their GPC.
} 
to 2004. This captures the changes in rainfall during 2005-2016 compared to 19942004, and matches the time-scale of the outcome variable. Data on temperature for the period 2005 to 2016 come from MOD11C3 MODIS and were used to establish monthly average temperature for the agricultural season (Wan et al., 2015).

In addition to household questionnaires, investigators obtained the actual number of members in the GPCs during an agricultural season from membership lists provided by the 2 cotton companies. This information was used to check the robustness of our results. Unfortunately, some farmers reported that they belonged to GPCs that are not identified in the list provided by SOFITEX and Faso Coton.

\section{Analytical Framework for the Adaptation Measures}

In this section, I introduce the dependent variables. The survey aimed to analyse cotton farmers' adaptation strategies in response to climatic change in Burkina Faso. The questionnaire investigated whether farmers had noticed changes in temperature and rainfall trends since 2000. 100\% of the sample had perceived changes in mean rainfall and $91 \%$ in mean temperature, which is consistent with the actual changes in the weather. This observation is in line with Kosmowski et al. (2016) who find that smallholders living in rural dry areas have a higher level of awareness about local changes. The farmers were also asked whether they had responded to these changes by adaptation measures in the last 10 years. I use their answers to distinguish incremental adaptation strategies from transformational adaptation strategies, and analyse the impact of the professional network on both strategies.

The IPCC defines two categories of adaptation strategies in response to climate change (Field et al., 2014). Incremental adaptations are "adaptation actions where the central aim is to maintain the essence and integrity of a system or process at a given scale". These strategies seek to preserve existing locations, livelihoods, and forms of production while making them more resilient. In this context, systems keep their way of functioning with efforts made towards more resilience to climate hazards and to climate change. Alternative definitions of incremental adaptations retain the spirit of the IPCC view. For instance, Fook (2017) describes incremental adaptation as "adjustments made to manage proximate climate risks and impacts while retaining the function and resilience of existing structures and policy objectives". 
Table 1: Summary statistics for independent variables

\begin{tabular}{|c|c|c|c|c|c|}
\hline Variables $^{\text {a }}$ & Mean & $\mathrm{SD}{ }^{\mathrm{b}}$ & Min & $\operatorname{Max}$ & Obs \\
\hline Self-reported number of members of the GPC ${ }^{c}$ & 50.15 & 39.41 & 3 & 136 & 666 \\
\hline Mean Distance to other farmers in the GPC & 2.62 & 5.58 & 0 & 108 & 665 \\
\hline Age of household head (years) ${ }^{d}$ & 49.00 & 12.63 & 18 & 88 & 660 \\
\hline Constructed Wealth Index & -0.00 & 1.76 & -8 & 2 & 668 \\
\hline $\begin{array}{l}\text { Farmer received Education from primary school }(1=\text { yes } \\
0=\text { otherwise })\end{array}$ & 0.34 & 0.48 & 0 & 1 & 668 \\
\hline Access to Early Warning Systems $(1=$ yes $0=$ otherwise $)$ & 0.52 & 0.50 & 0 & 1 & 668 \\
\hline Total Labour per hectare used for cotton production & 25.94 & 29.43 & 0 & 214 & 663 \\
\hline Land used for cotton production (hectares) & 1.54 & 1.65 & 0 & 15 & 664 \\
\hline \multicolumn{6}{|l|}{ Information about the GPC environment } \\
\hline GPC helps against climate change $(1=$ yes $0=$ otherwise $)$ & 0.64 & 0.48 & 0 & 1 & 668 \\
\hline GPC helps with money transfers $(1=$ yes $0=$ otherwise $)$ & 0.16 & 0.37 & 0 & 1 & 668 \\
\hline GPC provides agricultural advice $(1=$ yes $0=$ otherwise $)$ & 0.12 & 0.32 & 0 & 1 & 668 \\
\hline \multicolumn{6}{|l|}{ Information about Climate } \\
\hline $\begin{array}{l}\text { Average cumulative Rainfall 2005-16/Average cumulative } \\
\text { rainfall 1994-2004 }\end{array}$ & 1.06 & 0.02 & 1.02 & 1.11 & 668 \\
\hline $\begin{array}{l}\text { Average Temperature for the rainy season over the period } \\
2005-2016\end{array}$ & 34.66 & 0.54 & 33.13 & 35.51 & 668 \\
\hline \multicolumn{6}{|l|}{ Instrumental Variables ${ }^{e}$} \\
\hline Number of GPC members in 2009 & 38.32 & 31.84 & 8 & 106 & 611 \\
\hline Insecticides distributed to the GPC in 2016 & 117.14 & 106.22 & 7 & 396 & 627 \\
\hline
\end{tabular}

a Text in bold refers to the names given to the variables for the following tables.

b "SD" stands for "Standard Deviations".

c "GPC" stands for "Cotton Producers' Group".

d For regressions below, I substitute missing data with the mean for the age variable, that is 49 .

e Information for instrumental variables comes from data provided by cotton companies and does not use statistics from individual surveys. 
In contrast, transformational adaptations is an action that "changes the fundamental attributes of a system in response to climate and its effects" (Field et al., 2014). Here, fundamental attributes refer to the function, structure, and identity that characterize a system. By definition, agents carry out transformational adaptations when they seek to reduce vulnerability or exposure to climate change by replacing existing systems with new ones. For example, in the context of this study, transformational actions might be transforming a system based on cotton production to other economic activities. Transformational adaptations, mainly defined as movement of people and activities across sectors and space, describe a long-term process of economic development.

My original hypothesis was that redistributive pressure would have diverse effects on risk-taking whether it relates to cotton production or not. Indeed, although the sharing obligation of the professional network may impact the decisions relative to the cotton sector, it is not clear whether it would also hamper transformational adaptations. Therefore, I follow the above definitions of incremental and transformational adaptations to classify the adaptation actions found in the questionnaire. I create 2 dummy variables, for incremental strategies and transformational strategies, equal to 1 if the farmer reported to have adopted at least one of the strategies referred in Table 2. Incremental adaptations focused on improvements in cotton management whereas transformational adaptations focused on alternative livelihood strategies, substitution of crops, or relocation. I exclude adaptation strategies such as change in seeds or fertilizer since those inputs are distributed by cotton companies to the whole cooperative and do not reflect individual choices. Crop rotation is the practice of growing different types of crops and rotating them according to the seasons. This technique is implemented by the farmer at the plot level and reflects individual choices. I am not aware of any training that would have been offered to the farmers in crop rotation. Since the classification is made arbitrarily according to my own understanding of the 2 concepts, I constrain transformational adaptation to a smaller range of more radical strategies in a robustness check.

\section{Econometric Strategy}

The purpose of this paper is to empirically investigate whether a professional network and joint liability reduce the willingness to self-protect in the face of climate change. 
Table 2: Classification and summary statistics for adaptation strategies

\begin{tabular}{lcc}
\hline \hline Adaptation Strategies (Dummies) & Mean & $\begin{array}{c}\text { Standard } \\
\text { Deviations }\end{array}$ \\
\hline Incremental Adaptation & 0.792 & 0.406 \\
\hline Soil and Water Conservation Techniques & 0.626 & 0.484 \\
Change in rotation of crops, including cotton & 0.588 & 0.493 \\
\hline Transformational Adaptation & 0.609 & 0.488 \\
\hline Migration of at least one member of the household & 0.001 & 0.039 \\
Increase of temporary mobility & 0.003 & 0.055 \\
Adoption of new crops & 0.133 & 0.340 \\
Stop growing some crops & 0.080 & 0.270 \\
Diversification to other agricultural activities & 0.451 & 0.498 \\
Diversification to herd breeding & 0.362 & 0.481 \\
Diversification to off-farm activities & 0.256 & 0.437 \\
Total stop of agricultural activities & 0.034 & 0.182 \\
\hline
\end{tabular}

To estimate how the probability of adopting risk-mitigating strategies is affected by the extent of the professional network, I use the self-reported size of the group and a set of controls. Let $A_{h}^{i}$ represent the i-th adaptation strategy (incremental or transformational) for household $h$. The extent of the network is represented by $N_{h}$ and associated with the parameter of interest $\beta_{1}^{i}$. $\epsilon_{h}^{i}$ is a household specific error terms. $X_{h}$ and $X_{h}^{c}$ are the vectors of household characteristics and climatic variables respectively, with their associated vector of parameters $\beta_{2}^{i}$ and $\beta_{3}^{i}$.

The empirical is as follows:

$$
A_{h}^{i}=\beta_{0}^{i}+\beta_{1}^{i} N_{h}+\beta_{2}^{i} X_{h}+\beta_{3}^{i} X_{h}^{c}+\epsilon_{h}^{i}
$$

$N_{h}$ is the self-reported number of members belonging to the same GPC for household $h$. Even though the self-reported size of the group may differ from the actual one, it constitutes a good proxy for the scope of the safety network upon which a household feels it relies on for help in times of hardship.

The simplest identification strategy assumes that the size of a farmer"s network is exogenous. This choice is motivated by arguments from the data, the history of GPCs, and some field expertise. First, from field testimonies the farmer is not able 
to promote competition between cotton companies by choosing, for instance, Sofitex instead of Faso Coton for her cooperative. Figure 1 illustrates how the country has divided its territory to let the cotton companies operate geographically as monopoly actors. As well as this monopoly (and monopsony) situation, the cotton companies informally require farmers to work together in a single cooperative per village. The data supports these field testimonies: out of the 32 villages in the sample, 22 (69\%) are registered as having only one GPC. Also, new cotton producers are often asked to join already existing cooperatives when they start their business. Cotton companies do not constrain the size of the cooperatives, which leads some of the surveyed groups to have more than a hundred farmers. This pattern shows the limited flexibility farmers can enjoy when it comes to choosing her cooperative, or to creating a new one.

The first econometric specifications for the empirical strategy build on the belief that the main variable of interest is exogenous and is not chosen by the farmer at the time of the survey. However, some theoretical studies highlight pre-existing social networks as a determining factor in group formation. Attanasio et al. (2012) investigate who pools risk with whom when trust is crucial for enforcing risk pooling arrangements. They find that close friends and relatives are more likely to join the same risk pooling group, while non-family non-friend participants join groups less. Therefore professional networks may strongly correlate with networks of kinship, caste, friendship, and geographic proximity (De Weerdt and Dercon, 2006; Fafchamps and Gubert, 2007; Munshi and Rosenzweig, 2009; Mazzocco and Saini, 2012). Because the farmers do not have access to a range of GPC opportunities, it is very likely that most of the cooperatives include members with strong social ties. This is also driven by the fact that the surveyed villages are small. Di Falco and Bulte (2013) find that compulsory sharing within families reduces farmers' incentives to adopt soil and conservation (SWC) techniques. In such a situation, the dependent and independent variables are correlated but the causal effects come from kinship pressure instead of professional pressure.

To improve the chance of capturing the impact of the professional network instead of the kinship network, I add a control. Because there is not enough information from the data to establish potential blood or kinship relationships between farmers, I control for social connectedness by using GPS coordinates to compute the distance 
between members of the same group. ${ }^{14}$ I follow the findings of Fafchamps and Gubert (2007) to control for interpersonal relationships with geographic proximity. The literature often describes geographical proximity as a driver of the monitoring intensity between peers (Armendáriz de Aghion, 1999). Therefore, geographical distance between producers can also be interpreted as an additional measure of social pressure.

The peer effects literature suggests that farmers with similar wealth characteristics are more likely to enter group contracts and share risk (Fafchamp and Lund, 2003; Johnson and Smirnov, 2018). Therefore, characteristics such as land, labour, and other socio-demographic variables, are used as controls to capture individual wealth or endowments. Given the dependence on climatic conditions for farming success, rainfall and temperature information allow the building of an additional specification. Asfaw et al. (2019) show that exposure to climate-related shocks in Sub-Saharan Africa is positively associated with transformational adaptations such as crop or livelihood diversification. In all the specifications, I include a cotton zone fixed effect to control for unobservable heterogeneity for cotton companies (Faso Coton and Sofitex). Standard errors are clustered at the village level in the main specifications, but Table A6 in the appendix shows alternative clustering.

Although farmers do not enjoy a wide range of opportunities in terms of GPC choice, the reverse causality issue of farmers self-selecting into larger groups cannot be entirely ruled out. It is likely that risk-averse actors would prefer big groups to make sure that they will have assistance from other members in case of harvest failure. That said, the main coefficient could illustrate the fact that risk-averse cotton farmers chose larger groups to broaden their safety network. Therefore, I implement an instrumental probit approach to deal with possible endogeneity of the network variable. The selection of instruments is complex since I need variables that are correlated with the professional network metric but not with the error term of the adaptation models. I provide test statistics to support the idea that instrumentation helps to strengthen the results but neither instrumental variable is perfect.

The first instrument is the total amount of pesticides allocated by cotton com-

\footnotetext{
${ }^{14}$ The distances are computed through a specific program in Stata using GPS coordinates (geodist). The new variable created captures the mean distance from individual $h$ to all other households belonging to the same GPC.
} 
panies to farmers for the 2015/2016 agricultural season. The quantity of pesticides distributed to the GPC should be related to the number of members. However, there is no reason to believe that pesticide supply could be correlated with past decisions to adapt to climate change. The pesticide intensiveness on fields is a solution to the risk of crop disease, but not related to weather-related risks. Crop diseases, the cotton bollworm Helicoverpa armigera in particular, represent a major threat for cotton producers in Burkina Faso (Cauquil and Vaissayre, 2000; Banwo and Adamu, 2003). ${ }^{15} 80 \%$ of the sample reports damage to their cotton production due to crop diseases in the last 10 years. To deal with this common risk, cotton companies provide pesticide to the farmers. This pesticide supply allows the disentanglement of risks induced by climate change from risks induced by pest pressure.

For the next instrument, I make use of the membership history and input data provided by the cotton companies. The second instrument is the lagged actual size of the GPC back to the 2008/2009 agricultural season as recorded by the cotton companies. The size of the GPC in 2008/2009 is likely to explain the self-reported number of members at the time of the survey (2015/2016), because there was no big change in the period. Whether it is correlated to error terms of adaptation measure is more debatable since most of the strategies began to be implemented by farmers after the devastating flood in September 2009. Two of the surveyed provinces, Kossi and Oubritenga, are in the regions which were most affected by this extreme event. The household-level questionnaires show that $78 \%$ of the sample suffered from big damage due to the flood.

A further step consists in controlling for heterogeneity between groups of cotton farmers. Including fixed effects at the group level would allow me to tackle unobservable heterogeneity. I use relevant answers from questionnaires to capture heterogeneity between groups of farmers. The survey gives information about the channels through which cotton producers take advantage of their group: GPC may bolster money transfers and/or better management of climate change. Considering the different benefits at the core of different GPCs, different attitudes to risk-mitigation may be triggered. Therefore, I introduce an additional specification with interactive variables to highlight the role of the group organization in the individual decisions

\footnotetext{
${ }^{15}$ cotton bollworm Helicoverpa armigera had high population densities in 1998 leading to massive yield reductions despite increased insecticide use in West Africa. The larvae of the bollworm has the capacity to cause up to $90 \%$ yield loss on cotton.
} 
to adapt to climate change.

\section{Results}

\section{Main results}

The main results are presented in Table 3. I focus on the effect of the number of members in the group of cotton producers on both incremental and transformational adaptation strategies. Specification (1) gives the results for the most parsimonious model with household characteristics. Specification (2) controls for weather variables that are most likely to influence adaptation decisions. Specification (3) includes additional fixed effects at the departements level. Some robustness checks test for the reliability of the results. Table 4 displays the estimates when the endogenous variable is instrumented with one instrument or/and the other.

The first result is that the self-reported size of the network is significantly correlated with a reduced probability to apply incremental adaptation risk-mitigation strategies for cotton growing. This result holds for all specifications, including the instrumental variables model which satisfies the appropriate test statistics. The Wald test shows that the standard probit estimation can be plagued by endogeneity bias (see Wald test statistics at the end of table 4). To probe if the instruments are relevant, I run the first-stage regression by regressing the network size variable against the instruments and the other exogenous variables. Both instruments significantly and positively correlate with the network variable.

For incremental adaptations, I estimated the average marginal effect for the network variable, it is -0.002. In other words, one new member joining the GPC reduces the probability of investing in incremental adaptation strategies by $0.2 \%$. If the average group size, which is about 50 farmers, increases by $10 \%$, the individual decision to adapt incremental strategies decreases by $1 \%$. The marginal effects from the instrumental probit regression produces a higher impact, with the same increase in group size leading to a $6.5 \%$ decrease in likelihood to adapt cotton production to climate change. The negative effect of the network size appears to be modest, but should not be underestimated for two reasons. First, field observations prove that one member rarely decides alone to leave one group and join another 
one. It is more likely that a whole small GPC would ask to merge with another to gain bargaining power against the cotton companies. In this case, the marginal effect on the decision to strengthen cotton production resilience is bigger. Second, existing fieldwork from Burkina Faso suggests that marginal returns on modest investments in water availability may be high in terms of yields (Sanders et al., 1996). Therefore, ignoring adaptation strategies, even though they are not onerous and big, can generate significant losses in yields.

Another interesting variable is the mean distance between one farmer and her GPC partners. When the distance to other cotton farmers increases, the household is significantly less likely to use risk-mitigating strategies for the cotton growing. This result holds only for the first specification. Being another proxy for social pressure, distance captures the similar idea that farmers who belong to an extended network (in space rather than numbers, in this case) have less incentive to consolidate their resilience to climate change. The average marginal effect is approximately 0.005: being even further (about one kilometre) from other members decreases the probability of adopting incremental strategies by $0.5 \%$.

In conclusion, for the incremental adaptation models the results provide significant evidence of negative incentive effects associated with mutual assistance. Under social pressure, farmers behave like free-riders and reduce their willingness to invest in more resilient methods for their cotton production.

Secondly, the estimates for transformational adaptation are qualitatively similar to the ones for incremental adaptation. This result is robust to all specifications for the probit model. However, results for the instrumented specification have not been interpreted since there is no evidence of possible endogeneity in this case (see the Wald test statistics at the end of Table 3). Adaptation strategies that could be implemented in parallel to the ones relative to the cotton sector are also negatively impacted by the network of cotton farmers. In addition to hampering risk-mitigating strategies for growing cotton, the structure of the professional network prevents small farmers from diversifying their activities towards other farm and non-farm activities. This means that the professional network impacts risk-mitigation strategies beyond cotton production and constrain farmers from broadening their source of revenues. The average marginal effect is such that one new member in the professional network significantly decreases the likelihood to enforce transformational adaptations 
Table 3: Regressions for Incremental and Transformational Adaptation to Climate Change

\begin{tabular}{|c|c|c|c|c|c|c|}
\hline & \multicolumn{3}{|c|}{ Incremental Adaptations } & \multicolumn{3}{|c|}{ Transformational Adaptations } \\
\hline & Probit (1) & Probit (2) & Probit (3) & Probit (1) & Probit (2) & Probit (3) \\
\hline Self-reported number of members & $\begin{array}{c}-0.005^{* *} \\
(0.006)\end{array}$ & $\begin{array}{c}-0.008^{* * *} \\
(0.007)\end{array}$ & $\begin{array}{c}-0.014^{* * *} \\
(0.010)\end{array}$ & $\begin{array}{c}-0.008^{* *} \\
(0.019)\end{array}$ & $\begin{array}{c}-0.009^{* * *} \\
(0.024)\end{array}$ & $\begin{array}{c}-0.014^{* * *} \\
(0.011)\end{array}$ \\
\hline Mean Distance & $\begin{array}{c}-0.010^{*} \\
(0.006)\end{array}$ & $\begin{array}{l}-0.011 \\
(0.007)\end{array}$ & $\begin{array}{l}-0.014 \\
(0.010)\end{array}$ & $\begin{array}{l}-0.016 \\
(0.019)\end{array}$ & $\begin{array}{l}-0.020 \\
(0.024)\end{array}$ & $\begin{array}{l}-0.009 \\
(0.011)\end{array}$ \\
\hline Age & $\begin{array}{c}0.019 * * * \\
(0.006)\end{array}$ & $\begin{array}{c}0.018^{* * *} \\
(0.005)\end{array}$ & $\begin{array}{c}0.016^{* * *} \\
(0.005)\end{array}$ & $\begin{array}{c}0.007 \\
(0.005)\end{array}$ & $\begin{array}{c}0.003 \\
(0.005)\end{array}$ & $\begin{array}{c}0.001 \\
(0.004)\end{array}$ \\
\hline Wealth Index & $\begin{array}{c}-0.240^{* * *} \\
(0.066)\end{array}$ & $\begin{array}{c}-0.181^{* * *} \\
(0.059)\end{array}$ & $\begin{array}{c}-0.139^{* * *} \\
(0.051)\end{array}$ & $\begin{array}{c}-0.270^{* * *} \\
(0.079)\end{array}$ & $\begin{array}{c}-0.222^{* * *} \\
(0.075)\end{array}$ & $\begin{array}{l}-0.049 \\
(0.066)\end{array}$ \\
\hline Education & $\begin{array}{c}0.193 \\
(0.118)\end{array}$ & $\begin{array}{c}0.175 \\
(0.119)\end{array}$ & $\begin{array}{c}0.160 \\
(0.128)\end{array}$ & $\begin{array}{c}0.276^{* *} \\
(0.116)\end{array}$ & $\begin{array}{c}0.245^{* *} \\
(0.117)\end{array}$ & $\begin{array}{c}0.175 \\
(0.117)\end{array}$ \\
\hline Early Warning Systems & $\begin{array}{l}-0.202 \\
(0.323)\end{array}$ & $\begin{array}{l}-0.035 \\
(0.316)\end{array}$ & $\begin{array}{c}0.694^{* *} \\
(0.298)\end{array}$ & $\begin{array}{c}1.035^{* * *} \\
(0.268)\end{array}$ & $\begin{array}{c}1.279^{* * *} \\
(0.248)\end{array}$ & $\begin{array}{c}1.623^{* * *} \\
(0.276)\end{array}$ \\
\hline Labour & $\begin{array}{c}0.001 \\
(0.004)\end{array}$ & $\begin{array}{c}0.002 \\
(0.004)\end{array}$ & $\begin{array}{c}0.003 \\
(0.004)\end{array}$ & $\begin{array}{c}0.008 \\
(0.006)\end{array}$ & $\begin{array}{c}0.009 \\
(0.006)\end{array}$ & $\begin{array}{c}0.005 \\
(0.005)\end{array}$ \\
\hline Lands & $\begin{array}{c}0.018 \\
(0.029)\end{array}$ & $\begin{array}{c}0.028 \\
(0.028)\end{array}$ & $\begin{array}{c}0.061^{*} \\
(0.033)\end{array}$ & $\begin{array}{c}0.015 \\
(0.035)\end{array}$ & $\begin{array}{c}0.033 \\
(0.037)\end{array}$ & $\begin{array}{c}0.043 \\
(0.041)\end{array}$ \\
\hline Climate Environment: & & & & & & \\
\hline Rainfall Ratio & & $\begin{array}{l}-11.709 \\
(12.365)\end{array}$ & $\begin{array}{c}22.020^{* *} \\
(10.678)\end{array}$ & & $\begin{array}{c}-32.426^{* * *} \\
(11.167)\end{array}$ & $\begin{array}{c}-38.859^{* * *} \\
(13.882)\end{array}$ \\
\hline Temperature & & $\begin{array}{c}0.586^{* * *} \\
(0.191)\end{array}$ & $\begin{array}{l}-0.116 \\
(0.218)\end{array}$ & & $\begin{array}{c}0.194 \\
(0.220)\end{array}$ & $\begin{array}{c}-0.536^{*} \\
(0.319)\end{array}$ \\
\hline Fixed Effect for Cotton Zone & Yes & Yes & Yes & Yes & Yes & Yes \\
\hline Fixed Effect for Departements & No & No & Yes & No & No & Yes \\
\hline No. of Observations & 660 & 660 & 660 & 660 & 660 & 660 \\
\hline Pseudo $R^{2}$ & 0.084 & 0.111 & 0.203 & 0.168 & 0.197 & 0.320 \\
\hline Marginal effects for $N_{h}$ & $\begin{array}{c}-0.002^{* *} \\
(0.001)\end{array}$ & $\begin{array}{c}-0.002^{* * *} \\
(0.001)\end{array}$ & $\begin{array}{c}-0.002^{* * *} \\
(0.001)\end{array}$ & $\begin{array}{c}-0.003^{* *} \\
(0.001)\end{array}$ & $\begin{array}{c}-0.003^{* * *} \\
(0.001)\end{array}$ & $\begin{array}{c}-0.003^{* * *} \\
(0.001)\end{array}$ \\
\hline
\end{tabular}

Standard errors clustered at village level in parentheses. Constant terms are not reported. ${ }^{*} p<0.10,{ }^{* *} p<0.05$, *** $p<0.01$. Probit (1) introduces results for the simplest probit regression with household characteristics and cotton zone fixed effects. Probit (2) introduces climate variables. Probit (3) corresponds to the model with departements fixed effects. 
Table 4: Regressions with instrumental variables for Incremental and Transformational Adaptation to Climate Change

\begin{tabular}{|c|c|c|c|c|c|c|}
\hline & \multicolumn{3}{|c|}{ Incremental Adaptations } & \multicolumn{3}{|c|}{ Transformational Adaptations } \\
\hline & $\begin{array}{l}\text { Instrument } \\
\text { (1) }\end{array}$ & $\begin{array}{c}\text { Instrument } \\
\text { (2) }\end{array}$ & Both & $\begin{array}{l}\text { Instrument } \\
\text { (1) }\end{array}$ & $\begin{array}{c}\text { Instrument } \\
(2)\end{array}$ & Both \\
\hline \multicolumn{7}{|l|}{ Second stage: } \\
\hline Self-reported number of members & $\begin{array}{c}-0.021^{* * *} \\
(0.005)\end{array}$ & $\begin{array}{c}-0.012^{* * * *} \\
(0.003)\end{array}$ & $\begin{array}{c}-0.013^{* * *} \\
(0.003)\end{array}$ & $\begin{array}{c}-0.022^{* * * *} \\
(0.007)\end{array}$ & $\begin{array}{c}-0.010^{* *} \\
(0.005)\end{array}$ & $\begin{array}{c}-0.011^{* *} \\
(0.005)\end{array}$ \\
\hline \multicolumn{7}{|l|}{ First stage: } \\
\hline Amount of insecticides & $\begin{array}{c}0.157^{* *} \\
(0.070)\end{array}$ & & $\begin{array}{c}0.048^{* *} \\
(0.023)\end{array}$ & $\begin{array}{c}0.157^{* *} \\
(0.070)\end{array}$ & & $\begin{array}{l}0.043^{*} \\
(0.023)\end{array}$ \\
\hline Size of GPC in 2009 & & $\begin{array}{c}1.041^{* * *} \\
(0.081) \\
\end{array}$ & $\begin{array}{c}0.967 * * * \\
(0.086) \\
\end{array}$ & & $\begin{array}{c}1.041^{* * * *} \\
(0.081) \\
\end{array}$ & $\begin{array}{c}0.977^{* * *} \\
(0.083) \\
\end{array}$ \\
\hline Controls & Yes & Yes & Yes & Yes & Yes & Yes \\
\hline Fixed Effect for Cotton Zone & Yes & Yes & Yes & Yes & Yes & Yes \\
\hline No. of Observations & 622 & 606 & 606 & 622 & 606 & 606 \\
\hline Marginal effects for $N_{h}$ & $\begin{array}{c}-0.021 * * * \\
(0.005)\end{array}$ & $\begin{array}{c}-0.012^{* * *} \\
(0.003)\end{array}$ & $\begin{array}{c}-0.013^{* * *} \\
(0.003)\end{array}$ & $\begin{array}{c}-0.022^{* * *} \\
(0.006)\end{array}$ & $\begin{array}{c}-0.010^{* *} \\
(0.005)\end{array}$ & $\begin{array}{c}-0.011^{* *} \\
(0.005)\end{array}$ \\
\hline $\operatorname{chi} 2(1)$ & 12.13 & 5.81 & 11.22 & 5.28 & 0.02 & 0.27 \\
\hline prob $>$ chi2 & 0.001 & 0.016 & 0.001 & 0.022 & 0.877 & 0.604 \\
\hline
\end{tabular}

Standard errors clustered at village level in parentheses. Constant terms are not reported. ${ }^{*} p<0.10,{ }^{* *} p<0.05$, *** $p<0.01$.

Instrument (1) corresponds to the estimation with the quantity of insecticides as unique instrumental variable. Instrument (2) only uses the size of GPC back to 2009 as instrumental variable. The last specification jointly analyses the two instrumental variables. Chi2 refers to the Wald test of the exogeneity of the instrumented variables. If the test statistic is not significant, there is not sufficient information in the sample to reject the null hypothesis of no endogeneity. The results include some estimates from the first stage regression to assess how strongly the instruments are correlated with the size of the cooperative.

Control variables are still the following: mean distance, age, wealth index, education, early warning systems, land area, labour, rainfall and temperature. 
by approx. $0.3 \%$. As explained previously, this seemingly modest result can have significant consequences on farmers' livelihoods.

Two interpretations can support this surprising outcome. First, larger networks are more powerful and have more efficient ways to control for potential investment in non-cotton activities. The use of the distributed inputs for alternative crops would be severely reprimanded, for example by exclusion from the GPC, and drive farmers to keep their focus on cotton production. The second explanation is based on the fact that cotton production is the main activity of the surveyed households. Cotton farmers with a larger network have a bigger safety net upon which they can fall back on in bad times. For other crops or activities, a similar risk-protection system does not exist. Therefore, farmers ignore potential alternative sources of income. In small groups however, cotton farmers cannot rely on such an extended network. They generally concentrate on limited issues where they face common risks, such as lack of rainfall, which could cause the whole group to lose their cotton harvest. To plan for this eventuality, farmers in small groups diversify their income sources and enforce transformational strategies to become more resilient to climate change.

Other variables deserve brief investigation to complete the empirical evidence of determinants to adapt in this context. Farmers working on plots where temperature for the last 10 years has been higher on average are significantly more likely to adopt risk-mitigating strategies on their cotton cultivated lands. Moreover, higher levels of rainfall scarcity significantly increase the adoption of transformational strategies. Table 3 introduces other interesting determinants of the decision to adapt to climate change that are in line with the previous literature. More educated farmers who usually benefit from a lower cost of information translates it into higher uptakes in adaptation strategies. Poorest smallholders - associated with a lower wealth index are more likely to implement - risk-mitigating strategies on their cotton cultivated land. Moreover, higher levels of rainfall scarcity significantly increase the adoption of transformational strategies. Table 3 introduces other interesting determinants of the decision to adapt to climate change that are in line with the previous literature. More educated farmers, who usually benefit from a lower cost of information, have a higher uptake of adaptation strategies. The poorer, small farmers, who have a lower wealth index, are more likely to implement risk-mitigating strategies under the threat of climate change. Since they own less assets, they take more risks to change 
their farming practices without the fear of losing much in case of failure. In other words, the opportunity cost of changing their daily life in order to adapt to climate change is smaller. Eventually, access to early warning systems significantly drives farmers to adopt transformational strategies by raising awareness of the possible future harmful climatic events.

\section{Channels: the cooperative's features}

Additional empirical evidence is crucial to better understand what drives farmers to behave as free-riders when they belong to larger groups. The intuition behind the main results is the following: to mitigate the harmful effects of climate change, smallholder farmers rely on the risk-pooling mechanisms instead of self-protecting. Once they belong to the cooperative, they expect the joint liability system to protect them in case of weather damaging events and the bigger the group, the bigger the probability that they are insured thanks to their peers. I next want to confirm that the risk-pooling system exists in the cooperative and how it affects adaptation decisions according to what extent joint liability is enforced. The aim here is to determine the specific GPC characteristics and conditions under which the results remain true. There are many reasons, other than joint liability pressure, which could drive the correlation between the size of the groups and the decisions to adapt to climate change. The main competitive explanation that might explain a lower likelihood to adopt in larger groups is the slower diffusion of agricultural advice. A larger group could make coordination more difficult, and the transmission of information longer, so that larger groups could tend to adapt later.

To test the assumption that farmers actually consider the cooperative to be a risk-pooling mechanism against climate change, further information is extracted from the data set. Cotton farmers were asked whether the cooperative helps them to adapt to climate change, whether the GPC fosters money transfers between producers, and whether it provides agricultural advice. ${ }^{16}$ I run 2 interaction models to separately study the impact of information and the impact of joint liability system according to the size of the group. Also, I run separate regression for Soil and Water Conservation techniques (SWC) since the implementation of this incremental strat-

\footnotetext{
${ }^{16}$ The three questions are distinct from one another.
} 
egy may entail an initial cost from which Rotation of crops is exempted. I expect the farmers to be more reluctant to adapt to climate change when the adaptation strategies are costly.

Table 5 displays the coefficients for the complete interaction term only. I follow advice from Brambor et al. (2006) and did not interpret the coefficients of constitutive terms. However, all the interaction terms are included in the specifications with control variables, and additional results are available in appendices A1 and A2. The results show that when farmers report that they belong to a GPC that both helps to adapt to climate change and facilitates money transfers, the likelihood of implementing SWC techniques is negatively and significantly affected by the size of the group. This result holds also for transformational adaptation strategies. This finding corroborates the intuition that farmers who can financially count on their partners rely on the risk-pooling mechanism to mitigate the harmful impact of climate change instead of implementing new strategies at the individual scale. This holds especially for costly adaptation practices such as investing in alternative SWC techniques.

The main alternative mechanism behind the negative correlation between decisions to adapt to climate change and the size of the cooperative might be assumed to be the diffusion of information and agricultural advice. In larger groups, diffusion of agricultural advice on how to adapt to climate change might be slower and delay the take-up of actions. The results rule out this explanation and show that in larger groups which combine the provision of agricultural advice and some help to fight climate change, farmers are more likely to undertake individual strategies to protect their income.

The interplay between GPC characteristics reveals the settings in which farmers are more likely to adopt free-riding behaviours. The risk-pooling system supplants individual self-protecting strategies to manage climatic risks when cooperatives are proved to enforce joint liability. This free-riding behaviour is strengthened by larger sizes of professional network. 
Table 5: Results of two interaction models with GPC characteristics

\begin{tabular}{lcccc}
\hline \hline & \multicolumn{2}{c}{ Incremental Adaptations } & \multirow{2}{*}{ Transformational } \\
& Total & SWC & Adaptations \\
\hline Money Transfers x Help against climate change x $N_{h}$ & -0.021 & $-0.030^{* *}$ & $-0.048^{* * *}$ \\
& $(0.016)$ & $(0.013)$ & $(0.016)$ \\
Agricultural advice x Help against climate change x $N_{h}$ & $0.064^{* * *}$ & $0.203^{* * *}$ & $0.038^{* * *}$ \\
& $(0.020)$ & $(0.013)$ & $(0.011)$ \\
\hline All constitutive terms & Yes & Yes & Yes \\
Controls & Yes & Yes & Yes \\
Fixed Effect for Cotton Zone & Yes & Yes & Yes \\
Fixed Effect for Departements & Yes & Yes & Yes \\
\hline \hline
\end{tabular}

Standard errors clustered at village level in parentheses. Constant terms are not reported. ${ }^{*} p<0.10$, ** $p<0.05,{ }^{* * *} p<0.01$. GPC stands for "Group of Cotton Producers". SWC stands for "Soil and Water Conservation Techniques". Control variables are still the following: mean distance, age, wealth index, education, early warning systems, land area, labour, rainfall and temperature. " $N_{h}$ stands for the self-reported number of members in the cooperative. The two variables displayed here are the final results from two separate regression models detailed in appendices A1 and A2.

\section{Robustness Checks}

In this section, I check the robustness of estimates by running additional regressions for the most complete probit specification which includes weather variables and fixed effects.

\section{Alternative measures for independent and dependent variables:}

Table A3 presents the results for alternative measures of network size. In this model, I test whether the results are robust to the actual size of the network instead of considering the self-reported size of the network. I use information from the two cotton companies who listed the farmers for most of the GPCs and allowed investigators to establish the actual size of groups. Unfortunately, this information was not available for some groups and explains the lower number of observations compared to previous regressions. The results in columns (1) and (2) are qualitatively and quantitatively very close to what was previously found: they show evidence of free-rider behaviour from farmers belonging to larger groups.

I test for a more restrictive interpretation of transformational adaptations to climate change in Table A3, column (3). Transformational adaptations are actions which "change the fundamental attributes of a system in response to climate and its effects". This time, I exclude from the transformational category any strategy that 
consists in just reorganizing farming activities, and focus on radical actions such as diversification off off-farm activities, total pull out from agriculture, temporal mobility, and migration. Following the new definition, the percentage of farmers who adopted transformational strategies falls from $61 \%$ to $29 \%$. Again, incentives to move across space and sector, and to radically change livelihoods, are significantly hindered by larger professional networks.

\section{Extensions to Probit Model:}

As a further robustness test, I estimate a bivariate probit model. When we jointly consider the two adaptation strategies, the results are still consistent. The testing procedure on the correlation coefficient of the error terms indicates that the null hypothesis of zero correlation can be rejected, meaning that the two adaptation strategies are often jointly undertaken. Table A4 presents results in line with previous findings.

Finally, I run an ordered probit model to assess how the intensity of adoption is affected by the size of the professional network. For the incremental adaptation, I create a category variable equal to 0 if the farmer did not adopt any strategy $21 \%$ of the sample, equal to 1 if she adopted one strategy - $37 \%$, and equal to 2 if she decided to adopt both SWC techniques and rotation in crops $-42 \%$. Since adaptation strategies defined as transformational are more numerous, I extend the previous categorization to a case where farmers adopt 3 or more transformational actions. The sample has $38 \%$ of farmers who did not adopt any transformational strategy, $16 \%$ who adopted 1 strategy, $27 \%$ who adopted 2 strategies, and $19 \%$ who adopted 3 or more strategies. In sub-Saharan countries, agricultural strategies to adapt to climate change are more effective when they are jointly implemented rather than isolated. For instance, the resilience of farmers who use soil and water conservation techniques increases when these strategies are coupled with change in crops (Di Falco and Veronesi, 2013; Di Falco, 2014). This highlights the importance of not implementing incremental strategies in isolation. The results from Table A5 the size of the cooperative is associated with the highest level of adaptation intensity. Estimated marginal effects for our main variable of interest allow deepening of the understanding: one additional member in the group does not reduce the incentives to adopt at least one adaptation strategy, but decreases the probability of adopting more than one strategy. These results again demonstrate the individual's lax 
approach to climate change when cooperatives are bigger.

\section{Discussion and conclusions}

The anthropological literature pioneered the idea that sharing obligations may lead to negative incentive effects and hold back investment for improving productive activities. Recently, economics researchers have investigated this question but evidence remains incomplete. In this paper, I test this idea by exploring the role of risk-sharing networks on the uptake of weather shock management strategies in Burkina Faso. The results of this empirical analysis indicate that a system based on mutual assistance between farmers may reduce efforts to adopt techniques that mitigate exposure to climate change. This conclusion holds for both incremental and transformational risk-mitigating strategies, showing that the Burkina Faso cotton farm management model has behavioural and economic implications beyond its core sector. This case illustrates that in the farmers' professional network, the principle of forced solidarity (sharing obligations leading to negative economic incentive effects) occurs. This research takes advantage of a range of statistical models which try to establish a significant and robust correlation between the two phenomena. However, these results use exclusively cross-sectional data from one agricultural season, making it complicated to turn the correlations into strong causal inference. Additional data, such as panel data or repeated cross sections, would allow more robust evidence on the role played by mutual assistance in boosting or hampering individual decisions to adapt to climate change.

Analysing how sharing obligations may become a barrier to adoption of new methods is crucial in the Sahelian context. Changing temperature and precipitation levels caused by climate change are expected to threaten rain-fed farming systems, like cotton. It represents an important obstacle for the livelihoods and well-being of farmers in semi-arid lands. They react autonomously to changing environmental conditions by smoothing water availability for their crops or by switching towards activities or to crops less dependent on rainfall levels. However, the existence of compulsory risk management mechanisms may lead farmers to ignore self-protection measures. By requiring producers to join in risk-pooling groups, cotton companies create pressure to redistribute the yields from the more productive farmers to the 
less successful ones. Therefore, larger groups drive down the incentives to implement autonomous risk-mitigating strategies. However, I do not reject the potential benefits of such a binding joint liability system. For some actors, this form of organization has been proven to be beneficial. On the one hand, the cotton companies which finance the purchases of inputs, can protect themselves from unpaid bills. On the other hand, the cotton farmers may consider these GPC to be a relevant form of safety net when alternative market or institutional mechanisms fail to protect them. However, complementary mechanisms need to be considered to help farmers to reduce their vulnerability to climate change. In the Burkina Faso cotton sector provision of alternative formal risk management mechanisms, such as insurance, is implemented and could be developed to boost decisions to adapt to climate change. By relaxing network pressure on the more productive farmers, group insurance contracts can reduce the likelihood of free-riding on peers to pay for purchases. 


\section{References}

Angelsen, A., Jagger, P., Babigumira, R., Belcher, B., Hogarth, N. J., Bauch, S., Börner, J., Smith-Hall, C., and Wunder, S. (2014). Environmental Income and Rural Livelihoods: A Global-Comparative Analysis. World Development, 64:S12S28.

Antwi-Agyei, P., Dougill, A. J., Stringer, L. C., and Codjoe, S. N. A. (2018). Adaptation opportunities and maladaptive outcomes in climate vulnerability hotspots of northern Ghana. Climate Risk Management, 19:83-93.

Armendáriz de Aghion, B. (1999). On the design of a credit agreement with peer monitoring. Journal of Development Economics, 60(1):79-104.

Asfaw, S., Scognamillo, A., Caprera, G. D., Sitko, N., and Ignaciuk, A. (2019). Heterogeneous impact of livelihood diversification on household welfare: Crosscountry evidence from Sub-Saharan Africa. World Development, 117:278-295.

Attanasio, O., Barr, A., Cardenas, J. C., Genicot, G., and Meghir, C. (2012). Risk Pooling, Risk Preferences, and Social Networks. American Economic Journal: Applied Economics, 4(2):134-167.

Baland, J.-M., Guirkinger, C., and Mali, C. (2011). Pretending to Be Poor: Borrowing to Escape Forced Solidarity in Cameroon. Economic Development and Cultural Change, 60(1):1-16.

Banwo, O. O. and Adamu, R. S. (2003). Insect pest management in African agriculture: Challenges in the current millenium. Archives of Phytopathology and Plant Protection, 36(1):59-68.

Beekman, G., Gatto, M., and Nillesen, E. (2015). Family Networks and Income Hiding: Evidence from Lab-in-the-Field Experiments in Rural Liberia. Journal of African Economies, 24(3):453-469.

Besley, T. and Coate, S. (1995). Group lending, repayment incentives and social collateral. Journal of Development Economics, 46(1):1-18.

Bezabih, M. and Sarr, M. (2012). Risk Preferences and Environmental Uncertainty: Implications for Crop Diversification Decisions in Ethiopia. Environmental and Resource Economics, 53(4):483-505. 
Blanc, E., Quirion, P., and Strobl, E. (2008). The climatic determinants of cotton yields: Evidence from a plot in West Africa. Agricultural and Forest Meteorology, 148(6):1093-1100.

Boltz, M., Marazyan, K., and Villar, P. (2019). Income hiding and informal redistribution: A lab-in-the-field experiment in Senegal. Journal of Development Economics, 137:78-92.

Brambor, T., Clark, W. R., and Golder, M. (2006). Understanding interaction models: improving empirical analyses. Political Analysis, 14:63-82.

Bryan, E., Ringler, C., Okoba, B., Roncoli, C., Silvestri, S., and Herrero, M. (2013). Adapting agriculture to climate change in Kenya: Household strategies and determinants. Journal of Environmental Management, 114:26-35.

Cassar, A., Healy, A., and von Kesser, C. (2011). Trust, risk, and time preferences after a natural disaster: Experimental evidence from thailand. University of California, San Francisco.

Castells-Quintana, D., Lopez-Uribe, M. d. P., and McDermott, T. K. J. (2018). Adaptation to climate change: A review through a development economics lens. World Development, 104:183-196.

Cauquil, J. and Vaissayre, M. (2000). Principaux ravageurs et maladies du cotonier en Afrique au sud du Sahara. Paris, France, CIRAD.

Cook, K. H. and Vizy, E. K. (2006). Coupled Model Simulations of the West African Monsoon System: Twentieth- and Twenty-First-Century Simulations. Journal of Climate, 19(15):3681-3703.

De Graeve, M., Elsen, W., and Razac Napon, A. (2017). De la françafrique à la corruption: les dessous de la filière coton au burkina-faso.

De Weerdt, J. and Dercon, S. (2006). Risk-sharing networks and insurance against illness. Journal of Development Economics, 81(2):337-356.

Di Falco, S. (2014). Adaptation to climate change in sub-saharan agriculture : Assessing the evidence and rethinking the drivers. European Review of Agricultural Economics, 41(3):405-430. 
Di Falco, S. and Bulte, E. (2013). The Impact of Kinship Networks on the Adoption of Risk-Mitigating Strategies in Ethiopia. World Development, 43:100-110.

Di Falco, S., Feri, F., Pin, P., and Vollenweider, X. (2018). Ties that bind: Network redistributive pressure and economic decisions in village economies. Journal of Development Economics, 131:123-131.

Di Falco, S. and Veronesi, M. (2013). How african agriculture can adapt to climate change? a counterfactual analysis from ethiopia. Land Economics, 89(4):743-766.

Durkheim, E. (1997). The division of labor in society. New York: Free Press.

Elum, Z. A., Modise, D. M., and Marr, A. (2017). Farmer's perception of climate change and responsive strategies in three selected provinces of South Africa. Climate Risk Management, 16:246-257.

Englebert, P. (1996). Burkina Faso : Unsteady Statehood In West Africa. Westview, Boulder.

Fafchamp, M. and Lund, S. (2003). Risk-sharing networks in rural philippines. Journal of Development Economics, 71:261-287.

Fafchamps, M. and Gubert, F. (2007). Risk Sharing and Network Formation. American Economic Review, 97(2):75-79.

Field, C. B., Barros, V. R., and on Climate Change, I. P., editors (2014). Climate change 2014: impacts, adaptation, and vulnerability: Working Group II contribution to the fifth assessment report of the Intergovernmental Panel on Climate Change. Cambridge University Press, New York, NY.

Fook, T. C. T. (2017). Transformational processes for community-focused adaptation and social change: a synthesis. Climate and Development, 9(1):5-21.

Funk, C., Peterson, P., Landsfeld, M., Pedreros, D., Verdin, J., Shukla, S., Husak, G., Rowland, J., Harrison, L., Hoell, A., and Michaelsen, J. (2015). The climate hazards infrared precipitation with stations - a new environmental record for monitoring extremes. Scientific Data, 2:150066.

Granovetter, M. (1983). The Strength of Weak Ties: A Network Theory Revisited. Sociological Theory, 1:201-233. 
Grimm, M., Hartwig, R., and Lay, J. (2017). Does forced solidarity hamper investment in small and micro enterprises? Journal of Comparative Economics, $45(4): 827-846$.

Hadness, M., Kosfeld, M., and Vollan, B. (2013). The dark side of solidarity. Technical.

Hassan, R. M. and Nhemachena, C. (2008). Determinants of African farmers'strategies for adapting to climate change: Multinomial choice analysis.

Jakiela, P. and Ozier, O. (2016). Does Africa Need a Rotten Kin Theorem? Experimental Evidence from Village Economies. The Review of Economic Studies, 83(1):231-268.

Johnson, T. and Smirnov, O. (2018). Inequality as information: Wealth homophily facilitates the evolution of cooperation. Scientific Reports, 8(1):1-10.

Kaminski, J. (2014). Subjective Wealth and Satisfaction with Policy Reform: Evidence from the Cotton Reform Experience in Burkina Faso. Journal of African Economies, 23(4):528-581.

Kaminski, J., Headey, D., and Bernard, T. (2011). The Burkinabè Cotton Story 1992-2007: Sustainable Success or Sub-Saharan Mirage? World Development, 39(8):1460-1475.

Kaminski, J. and Thomas, A. (2011). Land Use, Production Growth, and the Institutional Environment of Smallholders: Evidence from Burkinabè Cotton Farmers. Land Economics, 87(1):161-182.

Kates, R. W., Travis, W. R., and Wilbanks, T. J. (2012). Transformational adaptation when incremental adaptations to climate change are insufficient. Proceedings of the National Academy of Sciences of the United States of America, 109(19):7156-7161.

Kosmowski, F., Leblois, A., and Sultan, B. (2016). Perceptions of recent rainfall changes in Niger: a comparison between climate-sensitive and non-climate sensitive households. Climatic Change, 135(2):227-241. 
Kotir, J. H. (2011). Climate change and variability in Sub-Saharan Africa: a review of current and future trends and impacts on agriculture and food security. Environment, Development and Sustainability, 13(3):587-605.

Mazzocco, M. and Saini, S. (2012). Testing Efficient Risk Sharing with Heterogeneous Risk Preferences. American Economic Review, 102(1):428-468.

Munshi, K. and Rosenzweig, M. (2009). Why is Mobility in India so Low? Social Insurance, Inequality, and Growth. Technical Report 14850, National Bureau of Economic Research, Inc.

Patacchini, E. and Zenou, Y. (2008). The strength of weak ties in crime. European Economic Review, 52(2):209-236.

Platteau, J.-P. (2000). Institutions, Social Norms, and Economic Development. Psychology Press.

Platteau, J.-P. (2014). Redistributive Pressures in Sub-Saharan Africa: Causes, Consequences, and Coping Strategies.

Sanders, J. H., Shapiro, B. I., and Ramaswamy, S. (1996). The economics of agricultural technology in semiarid sub-Saharan Africa. The economics of agricultural technology in semiarid sub-Saharan Africa.

Schwartz, A. (1996). Attitudes to cotton growing in Burkina Faso : different farmers, different behaviours. In Benoit-Cattin, M., Griffon, M., and Guillaumont, P., editors, Economics of agricultural policies in developing countries, pages 341-363. Revue Française d'Economie, Paris.

Sivakumar, M. V. K. (1988). Predicting rainy season potential from the onset of rains in Southern Sahelian and Sudanian climatic zones of West Africa. Agricultural and Forest Meteorology, 42(4):295-305.

Squires, M. (2016). Kinship Taxation as an Impediment to Growth: Experimental Evidence from Kenyan Microenterprises. page 74.

Sultan, B., Baron, C., Dingkuhn, M., Sarr, B., and Janicot, S. (2005). Agricultural impacts of large-scale variability of the West African monsoon. Agricultural and Forest Meteorology, 128(1):93-110. 
Thomas, D. S. G., Twyman, C., Osbahr, H., and Hewitson, B. (2007). Adaptation to climate change and variability: farmer responses to intra-seasonal precipitation trends in South Africa. Climatic Change, 83(3):301-322.

Vitale, J. (2018). Economic importance of cotton in Burkina Faso. Technical report, Food and Agriculture Organization of the United Nations (FAO).

Voors, M., Nillesen, E., Verwimp, P., Bulte, E., and van Soest, D. (2012). Violent conflict and behavior: A field experiment in burundi. American Economic Review, $102(2): 941-964$.

Wan, Z., Hook, S., and Hulley, G. (2015). MOD11c3 MODIS/Terra Land Surface Temperature/Emissivity Monthly L3 Global 0.05deg CMG V006. 
Appendices 
Table A1: Results of Interaction Models with GPC characteristics

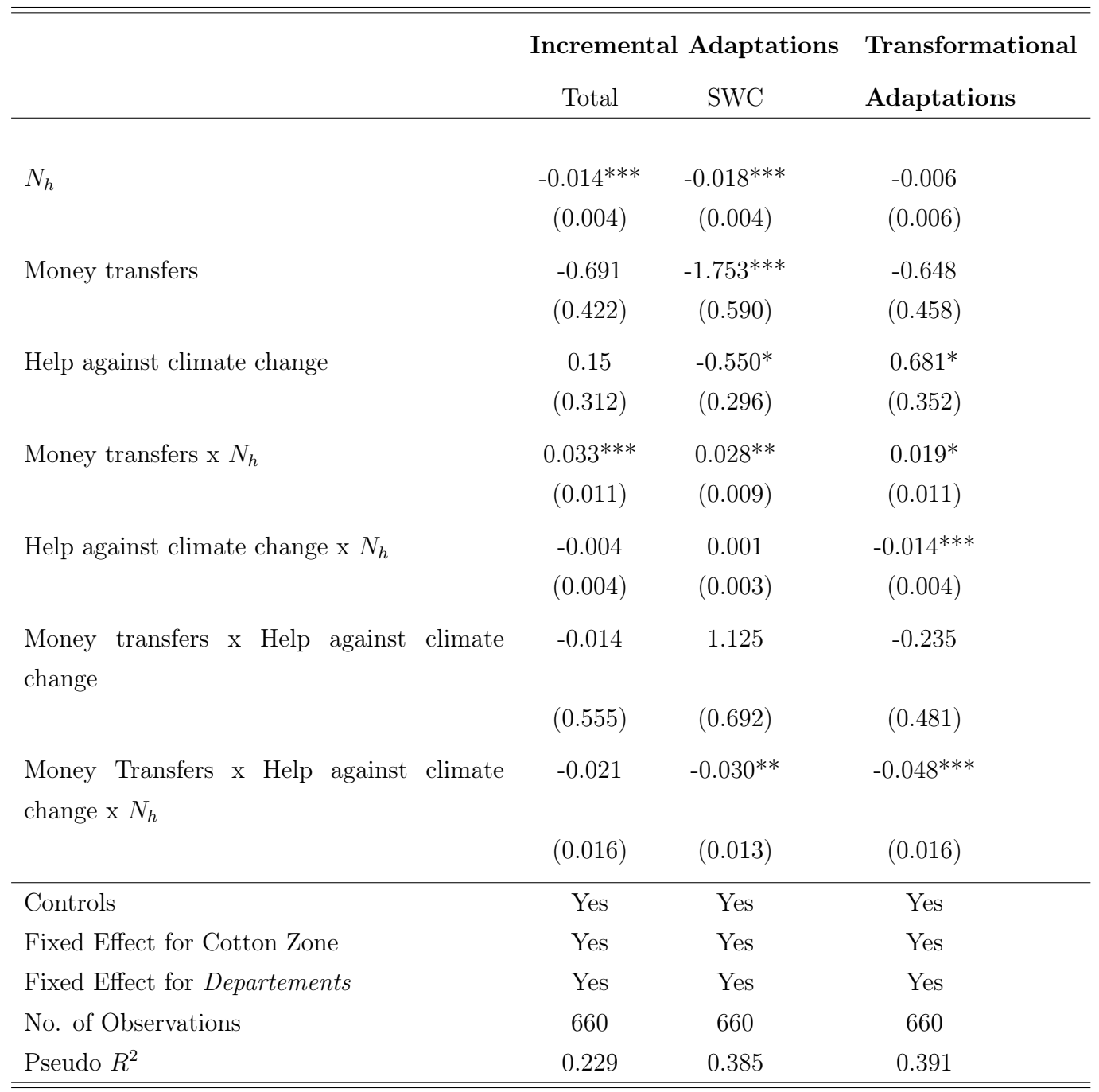

Standard errors clustered at village level in parentheses. Constant terms are not reported. ${ }^{*} p<0.10$, ** $p<0.05,{ }^{* * *} p<0.01$. GPC stands for "Group of Cotton Producers". $N_{h}$ is the self-reported number of members. SWC stands for "Soil and Water Conservation Techniques". Control variables are still the following: mean distance, age, wealth index, education, early warning systems, lands, labour, rainfall, and temperature. 
Table A2: Results of Interaction Models with GPC characteristics

\begin{tabular}{|c|c|c|c|}
\hline & \multicolumn{2}{|c|}{ Incremental Adaptations } & \multirow{2}{*}{$\begin{array}{l}\text { Transformational } \\
\text { Adaptations }\end{array}$} \\
\hline & Total & SWC & \\
\hline \multirow[t]{2}{*}{$N_{h}$} & $-0.011^{* *}$ & $-0.009^{* *}$ & -0.003 \\
\hline & $(0.004)$ & $(0.005)$ & $(0.005)$ \\
\hline \multirow[t]{2}{*}{ Agricultural advice } & $4.654^{* * *}$ & $12.551^{* * *}$ & 1.392 \\
\hline & $(0.564)$ & $(0.702)$ & $(0.906)$ \\
\hline \multirow[t]{2}{*}{ Help against climate change } & 0.159 & -0.087 & 0.408 \\
\hline & $(0.360)$ & $(0.316)$ & $(0.430)$ \\
\hline \multirow{2}{*}{ Agricultural advice x $N_{h}$} & $-0.010^{*}$ & $-0.178^{* * *}$ & -0.014 \\
\hline & $(0.006)$ & $(0.008)$ & $(0.010)$ \\
\hline \multirow[t]{2}{*}{ Help against climate change x $N_{h}$} & $-0.007^{*}$ & $-0.009 *$ & $-0.015^{* * *}$ \\
\hline & $(0.004)$ & $(0.005)$ & $(0.006)$ \\
\hline \multirow{2}{*}{$\begin{array}{l}\text { Agricultural advice x Help against climate } \\
\text { change }\end{array}$} & $-5.800^{* * *}$ & $-13.449^{* * *}$ & -1.474 \\
\hline & $(0.708)$ & $(0.639)$ & $(0.991)$ \\
\hline \multirow{2}{*}{$\begin{array}{l}\text { Agricultural advice x Help against climate } \\
\text { change x } N_{h}\end{array}$} & $0.064^{* * *}$ & $0.203^{* * *}$ & $0.037^{* * *}$ \\
\hline & $(0.020)$ & $(0.013)$ & $(0.011)$ \\
\hline Controls & Yes & Yes & Yes \\
\hline Fixed Effect for Cotton Zone & Yes & Yes & Yes \\
\hline Fixed Effect for Departements & Yes & Yes & Yes \\
\hline No. of Observations & 660 & 660 & 660 \\
\hline Pseudo $R^{2}$ & 0.225 & 0.385 & 0.354 \\
\hline
\end{tabular}

Standard errors clustered at village level in parentheses. Constant terms are not reported. ${ }^{*} p<0.10$, ** $p<0.05,{ }^{* * *} p<0.01$. GPC stands for "Group of Cotton Producers". $N_{h}$ is the self-reported number of members. SWC stands for "Soil and Water Conservation Techniques". Control variables are still the following: mean distance, age, wealth index, education, early warning systems, lands, labour, rainfall, and temperature. 
Table A3: Results with new definitions of independent variable and dependant variable

\begin{tabular}{lccc}
\hline \hline & $\begin{array}{c}\text { Incremental } \\
\text { Adaptations }\end{array}$ & $\begin{array}{c}\text { Transformational } \\
\text { Adaptations }\end{array}$ & $\begin{array}{c}\text { Transformational } \\
\text { Adaptations }\end{array}$ \\
& $(1)$ & $(2)$ & $(3)$ \\
\hline Self-reported number of members & & & $-0.011^{* * *}$ \\
& & $-0.027^{* * *}$ & \\
Actual number of members & $-0.021^{* * *}$ & $(0.005)$ & \\
& $(0.004)$ & Yes & Yes \\
\hline Controls & Yes & Yes & Yes \\
Fixed Effect for Cotton Zone & Yes & Yes & Yes \\
Fixed Effect for Departements & Yes & 623 & 659 \\
No. of Observations & 591 & 0.364 & 0.260 \\
pseudo $R^{2}$ & 0.210 & & \\
\hline \hline
\end{tabular}

Standard errors clustered at village level in parentheses. Constant terms are not reported. ${ }^{*} p<0.10,{ }^{* *} p<0.05,{ }^{* * *} p<0.01$. GPC stands for "Group of Cotton Producers". Specifications (1) and (2) show the results with the alternative variable of interest, that is the actual number of members in the cooperative. Specification (3) introduces coefficients for a restrained definition of transformational adaptations. Control variables are still the following: mean distance, age, wealth index, education, early warning systems, lands, labour, rainfall, and temperature. 
Table A4: Biprobit Model for Incremental and Transformational Adaptations

\begin{tabular}{|c|c|c|}
\hline & $\begin{array}{l}\text { Incremental } \\
\text { Adaptations }\end{array}$ & $\begin{array}{c}\text { Transformational } \\
\text { Adaptations }\end{array}$ \\
\hline Self-reported number of members & $\begin{array}{c}-0.015^{* * *} \\
(0.003)\end{array}$ & $\begin{array}{c}-0.014^{* * *} \\
(0.003)\end{array}$ \\
\hline Mean Distance & $\begin{array}{l}-0.017 \\
(0.015)\end{array}$ & $\begin{array}{l}-0.006 \\
(0.009)\end{array}$ \\
\hline Age & $\begin{array}{c}0.016^{* * *} \\
(0.005)\end{array}$ & $\begin{array}{c}0.001 \\
(0.004)\end{array}$ \\
\hline Wealth Index & $\begin{array}{c}-0.129 * * * \\
(0.048)\end{array}$ & $\begin{array}{l}-0.045 \\
(0.066)\end{array}$ \\
\hline Education & $\begin{array}{c}0.178 \\
(0.118)\end{array}$ & $\begin{array}{c}0.173 \\
(0.109)\end{array}$ \\
\hline Early Warning Systems & $\begin{array}{l}0.769^{* *} \\
(0.305)\end{array}$ & $\begin{array}{c}1.601^{* * *} \\
(0.273)\end{array}$ \\
\hline Labour & $\begin{array}{c}0.003 \\
(0.004)\end{array}$ & $\begin{array}{c}0.005 \\
(0.005)\end{array}$ \\
\hline Lands & $\begin{array}{c}0.052 \\
(0.035)\end{array}$ & $\begin{array}{c}0.036 \\
(0.038)\end{array}$ \\
\hline Climate Environment: & & \\
\hline Rainfall Ratio & $\begin{array}{l}17.877^{*} \\
(10.634)\end{array}$ & $\begin{array}{c}-37.110^{* * *} \\
(13.434)\end{array}$ \\
\hline Average Temperature & $\begin{array}{l}-0.193 \\
(0.219)\end{array}$ & $\begin{array}{l}-0.448 \\
(0.305)\end{array}$ \\
\hline
\end{tabular}

Fixed Effect for Cotton Zone Yes

Fixed Effect for Departements $\quad$ Yes

athrho $1.012^{* * *}$

$(0.103)$

No. of Observations 660

Standard errors clustered at village level in parentheses. Constant terms are not reported. ${ }^{*} p<0.10,{ }^{* *} p<0.05,{ }^{* * *} p<0.01$.

Wald test of rho $=0$ : $\operatorname{chi} 2(1)=52.85$ Prob $>\operatorname{chi} 2=0.00$.

Marginal effects for $N_{h}$ : $\operatorname{Pr}($ incre $=1$, transfo $=1)=-0.003 * * *$ 
Table A5: Ordered Probit Model for Incremental and Transformational Adaptations

\begin{tabular}{|c|c|c|}
\hline & $\begin{array}{l}\text { Incremental } \\
\text { Adaptations }\end{array}$ & $\begin{array}{c}\text { Transformational } \\
\text { Adaptations }\end{array}$ \\
\hline Self-reported number of members & $\begin{array}{c}-0.009^{* * *} \\
(0.002)\end{array}$ & $\begin{array}{c}-0.008^{* * *} \\
(0.002)\end{array}$ \\
\hline Mean Distance & $\begin{array}{l}-0.025 \\
(0.017)\end{array}$ & $\begin{array}{l}-0.007 \\
(0.007)\end{array}$ \\
\hline Age & $\begin{array}{c}0.007 \\
(0.005)\end{array}$ & $\begin{array}{l}0.007^{*} \\
(0.004)\end{array}$ \\
\hline Wealth Index & $\begin{array}{c}-0.103^{* *} \\
(0.041)\end{array}$ & $\begin{array}{l}-0.020 \\
(0.040)\end{array}$ \\
\hline Education & $\begin{array}{c}0.053 \\
(0.095)\end{array}$ & $\begin{array}{l}0.195^{* *} \\
(0.092)\end{array}$ \\
\hline Early Warning Systems & $\begin{array}{c}0.901^{* * *} \\
(0.319)\end{array}$ & $\begin{array}{c}0.874^{* * *} \\
(0.184)\end{array}$ \\
\hline Labour & $\begin{array}{c}0.002 \\
(0.004)\end{array}$ & $\begin{array}{c}0.006 \\
(0.005)\end{array}$ \\
\hline Lands & $\begin{array}{l}-0.004 \\
(0.029)\end{array}$ & $\begin{array}{c}0.042 \\
(0.031)\end{array}$ \\
\hline \multicolumn{3}{|l|}{ Climate Environment: } \\
\hline Rainfall Ratio & $\begin{array}{l}15.872^{*} \\
(8.168)\end{array}$ & $\begin{array}{l}-23.747^{*} \\
(12.130)\end{array}$ \\
\hline Average Temperature & $\begin{array}{l}-0.134 \\
(0.172)\end{array}$ & $\begin{array}{l}-0.281 \\
(0.198)\end{array}$ \\
\hline $\begin{array}{l}\text { Fixed Effect for Cotton Zone } \\
\text { Fixed Effect for Departements } \\
\text { No. of Observations } \\
\text { pseudo } R^{2}\end{array}$ & $\begin{array}{c}\text { Yes } \\
\text { Yes } \\
660 \\
0.146\end{array}$ & $\begin{array}{l}\text { Yes } \\
\text { Yes } \\
660 \\
0.151\end{array}$ \\
\hline Estimated Mars & lal Effects of & \\
\hline Zero strategy adopted & $\begin{array}{c}0.003^{* * *} \\
(0.000)\end{array}$ & $\begin{array}{c}0.003^{* * *} \\
(0.001)\end{array}$ \\
\hline One strategy adopted & $\begin{array}{c}0.001^{* * *} \\
(0.000)\end{array}$ & $\begin{array}{c}0.000 \\
(0.000)\end{array}$ \\
\hline Two strategies adopted & $\begin{array}{c}-0.003^{* * *} \\
(0.001)\end{array}$ & $\begin{array}{c}-0.001^{* * *} \\
(0.000)\end{array}$ \\
\hline Three or more strategies adopted & & $\begin{array}{c}-0.002^{* * *} \\
(0.001)\end{array}$ \\
\hline
\end{tabular}

Standard errors clustered at village level in parentheses. Constant terms are not reported. ${ }^{*} p<0.10,{ }^{* *} p<0.05,{ }^{* * *} p<0.01$. 
Table A6: Regressions for Incremental and Transformational Adaptation to Climate Change

\begin{tabular}{|c|c|c|c|c|}
\hline & \multicolumn{2}{|c|}{ Cluster at GPC level } & \multicolumn{2}{|c|}{ Robust Standard Errors } \\
\hline & $\begin{array}{l}\text { Incremental } \\
\text { Adaptations }\end{array}$ & $\begin{array}{c}\text { Transformational } \\
\text { Adaptations }\end{array}$ & $\begin{array}{l}\text { Incremental } \\
\text { Adaptations }\end{array}$ & $\begin{array}{c}\text { Transformational } \\
\text { Adaptations }\end{array}$ \\
\hline Self-reported number of members & $\begin{array}{c}-0.014^{* * *} \\
(0.003)\end{array}$ & $\begin{array}{c}-0.014^{* * *} \\
(0.003)\end{array}$ & $\begin{array}{c}-0.014^{* * *} \\
(0.002)\end{array}$ & $\begin{array}{c}-0.014^{* * *} \\
(0.002)\end{array}$ \\
\hline Mean Distance & $\begin{array}{l}-0.014 \\
(0.009)\end{array}$ & $\begin{array}{l}-0.009 \\
(0.010)\end{array}$ & $\begin{array}{r}-0.014^{*} \\
(0.010)\end{array}$ & $\begin{array}{l}-0.009 \\
(0.010)\end{array}$ \\
\hline Age & $\begin{array}{c}0.016^{* * *} \\
(0.005)\end{array}$ & $\begin{array}{c}0.001 \\
(0.004)\end{array}$ & $\begin{array}{c}0.016^{* * *} \\
(0.005)\end{array}$ & $\begin{array}{c}0.001 \\
(0.005)\end{array}$ \\
\hline Wealth Index & $\begin{array}{c}-0.1139^{* *} \\
(0.056)\end{array}$ & $\begin{array}{l}-0.049 \\
(0.067)\end{array}$ & $\begin{array}{c}-0.139^{* *} \\
(0.056)\end{array}$ & $\begin{array}{l}-0.049 \\
(0.048)\end{array}$ \\
\hline Education & $\begin{array}{c}0.160 \\
(0.137)\end{array}$ & $\begin{array}{c}0.175 \\
(0.136)\end{array}$ & $\begin{array}{c}0.160 \\
(0.138)\end{array}$ & $\begin{array}{c}0.175 \\
(0.131)\end{array}$ \\
\hline Early Warning Systems & $\begin{array}{c}0.964^{* *} \\
(0.313)\end{array}$ & $\begin{array}{c}1.623^{* * *} \\
(0.286)\end{array}$ & $\begin{array}{c}0.964^{* * *} \\
(0.175)\end{array}$ & $\begin{array}{c}1.623^{* * *} \\
(0.212)\end{array}$ \\
\hline Labour & $\begin{array}{c}0.003 \\
(0.004)\end{array}$ & $\begin{array}{c}0.005 \\
(0.005)\end{array}$ & $\begin{array}{c}0.003 \\
(0.002)\end{array}$ & $\begin{array}{l}0.005^{* *} \\
(0.002)\end{array}$ \\
\hline Lands & $\begin{array}{c}0.061 \\
(0.046)\end{array}$ & $\begin{array}{c}0.043 \\
(0.043)\end{array}$ & $\begin{array}{c}0.061 \\
(0.044)\end{array}$ & $\begin{array}{c}0.043 \\
(0.040)\end{array}$ \\
\hline Climate Environment: & & & & \\
\hline Rainfall Ratio & $\begin{array}{l}22.020^{* *} \\
(11.231)\end{array}$ & $\begin{array}{c}-38.859^{* * *} \\
(14.700)\end{array}$ & $\begin{array}{l}22.020^{* *} \\
(10.133)\end{array}$ & $\begin{array}{c}-38.859^{* * *} \\
(10.162)\end{array}$ \\
\hline Temperature & $\begin{array}{l}-0.116 \\
(0.234) \\
\end{array}$ & $\begin{array}{r}-0.536^{*} \\
(0.283) \\
\end{array}$ & $\begin{array}{l}-0.116 \\
(0.224) \\
\end{array}$ & $\begin{array}{c}-0.536^{* *} \\
(0.212) \\
\end{array}$ \\
\hline Fixed Effect for Cotton Zone & Yes & Yes & Yes & Yes \\
\hline No. of Observations & 660 & 660 & 660 & 660 \\
\hline Pseudo $R^{2}$ & 0.203 & 0.320 & 0.203 & 0.320 \\
\hline
\end{tabular}

Standard errors are in parentheses. Constant terms are not reported. "GPC" stands for "Cotton Producers' Group". ${ }^{*} p<0.10,{ }^{* *} p<0.05,{ }^{* * *} p<0.01$. 